\title{
Catalytic Multicomponent Synthesis of Highly Substituted Pyrroles Utilizing a One-Pot Sila-Stetter/Paal-Knorr Strategy
}

\author{
Ashwin R. Bharadwaj and Karl A. Scheidt* \\ Department of Chemistry, Northwestern University, 2145 Sheridan Road, Evanston, Illinois, \\ 60208
}

\section{Supporting Information}

General Information: All reactions were carried out under a nitrogen atmosphere in flame-dried glassware with magnetic stirring. THF, $\mathrm{Et}_{2} \mathrm{O}, \mathrm{CH}_{2} \mathrm{Cl}_{2}$, DMF and toluene were purified by passage through a bed of activated alumina. ${ }^{1}$ Reagents were purified prior to use unless otherwise stated following the guidelines of Perrin and Armarego. ${ }^{2}$ Purification of reaction products was carried out by flash chromatography using EM Reagent silica gel 60 (230-400 mesh). Analytical thin layer chromatography was performed on EM Reagent $0.25 \mathrm{~mm}$ silica gel $60-\mathrm{F}$ plates. Visualization was accomplished with UV light and anisaldehyde, ceric ammonium nitrate stain, potassium permangenate, or phosphomolybic acid followed by heating. Melting points were obtained on a Thomas Hoover capillary melting point apparatus and are uncorrected. Infrared spectra were recorded on a Bio-Rad Win FT-IR spectrometer. ${ }^{1} \mathrm{H}-\mathrm{NMR}$ spectra were recorded on a Varian Inova $500(500 \mathrm{MHz})$ or Mercury $400(400 \mathrm{MHz})$ spectrometer and are reported in ppm using solvent as an internal standard $\left(\mathrm{CDCl}_{3}\right.$ at $\left.7.26 \mathrm{ppm}\right)$. Data are reported as ( $\mathrm{ap}=$ apparent, $\mathrm{s}=$ singlet, $\mathrm{d}=$ doublet, $\mathrm{t}=$ triplet, $\mathrm{q}=$ quartet, $\mathrm{m}=$ multiplet, $\mathrm{b}=$ broad $)$; coupling constant(s) is/are reported in Hz. Proton-decoupled ${ }^{13} \mathrm{C}-\mathrm{NMR}$ spectra were recorded on a Varian Inova $500(125 \mathrm{MHz})$ or Mercury $400(100 \mathrm{MHz})$ spectrometer and are reported in ppm using solvent as an internal standard $\left(\mathrm{CDCl}_{3}\right.$ at $\left.77.0 \mathrm{ppm}\right)$. Laser desorption mass spectra were obtained with PE BioSystems time-of-flight MALDI mass spectrometer with 2,5dihydroxybenzoic acid as matrix. Microwave reaction was done on a Biotage Emrys ${ }^{\mathrm{TM}}$ Creator.

Benzoyltrimethylsilane (1a), $p$-chlorobenzoyltrimethylsilane, and $p$-toluoyltrimethylsilane were prepared according to the procedure of Yamamoto and coworkers. ${ }^{3}$ Alkylacylsilanes were prepared using the procedure developed by Fleming and Ghosh. ${ }^{4}$ Chalcones were prepared according to the procedure of Murphy and Wattansin. ${ }^{5}$

\footnotetext{
1. Pangborn, A. B.; Giardello, M. A.; Grubbs, R. H.; Rosen, R. K.; Timmers, F. J. Organometal. 1996, 15, 15181520.

2. Perrin, D. D. and Armarego, W. L. Purification of Laboratory Chemicals; 3rd Ed., Pergamon Press, Oxford.1988.

3. Yamamoto, K.; Hayashi, A.; Suzuki S.; Tsuji, J. Organometal. 1987, 6, 974-979.

4. Fleming, I.; Ghosh U. J. Chem. Soc, Perkin Trans. 1. 1994, 257-262.

5. Murphy, W.S.; Wattansin, S. Synthesis 1980, 647-650.
} 


\section{General Procedure for Thiazolium Catalyzed Pyrrole Synthesis:}

A screw-capped test tube was charged with the thiazolium salt ( $14 \mathrm{mg}, 0.055 \mathrm{mmol}, 0.20$ equiv) in a nitrogen-filled drybox. The reaction vessel was removed from the box and placed under a positive pressure of nitrogen. Benzoyltrimethylsilane (100 mg, $0.55 \mathrm{mmol}, 2.0$ equiv) in THF $(0.25 \mathrm{~mL})$ was added by syringe to the test tube followed by the addition of DBU (13 $\mu \mathrm{L}, 0.083$ mmol, 0.30 equiv). The reaction mixture was heated to $70^{\circ} \mathrm{C}$ after which the chalcone $(0.275$ mmol, 1.0 equiv) in THF $(0.25 \mathrm{~mL})$ was added by syringe followed by the addition of 2 propanol $\left(83 \mu \mathrm{L}, 1.10 \mathrm{mmol}, 4.0\right.$ equiv). The reaction was allowed to stir at $70^{\circ} \mathrm{C}$ for 12 hours or until completion as determined by TLC (40\% ether/hexanes). To the solution amine $(0.825$ mmol, 3.0 equiv) was added followed by addition of $p$-toluenesulfonic acid (104 $\mathrm{mg}, 0.55 \mathrm{mmol}$, 2.0 equiv) in ethanol $(0.5 \mathrm{~mL})$ and $4 \AA$ molecular sieves (spatula tip). The reaction mixture remained heating at $70^{\circ} \mathrm{C}$ for an additional 6 to 12 hours or until consumption of diketone as determined by TLC ( $25 \%$ ethyl acetate/ hexane). Upon cooling to room temperature, the reaction mixture was diluted with ethyl acetate $(30 \mathrm{~mL})$ and washed with water $(10 \mathrm{~mL})$. The aqueous layer was washed with ethyl acetate $(3 \mathrm{X} 30 \mathrm{~mL})$ and the combined the organic extracts were washed with brine $(10 \mathrm{~mL})$ and dried over sodium sulfate, filtered, and concentrated in vасио. The resulting residue was purified by flash column chromatography on silica gel.

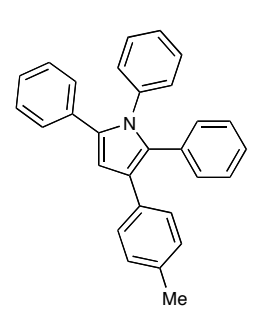

1,2,5-triphenyl-3-p-tolyl-1-H-pyrrole (6): Purified with 2\% ethyl acetate/hexanes, yielding $74 \mathrm{mg}(70 \%)$ of $\mathbf{6}$ as a white solid. $\mathrm{R}_{f}=0.83(25 / 75$ ethyl acetate/hexanes); mp: $156-160^{\circ} \mathrm{C} .{ }^{1} \mathrm{H}$ NMR $\left(500 \mathrm{MHz}, \mathrm{CDCl}_{3}\right) \delta 7.22-$ $7.01(\mathrm{~m}, 19 \mathrm{H}), 6.73(\mathrm{~s}, 1 \mathrm{H}), 2.34(\mathrm{~s}, 3 \mathrm{H}) ;{ }^{13} \mathrm{C} \mathrm{NMR}\left(125 \mathrm{MHz}, \mathrm{CDCl}_{3}\right) \delta$ 139.1, $135.3,134.9,133.4,133.2,133.1,131.8,129.4,129.2,128.8,128.7,128.3$, 128.2, 128.1, 127.2, 126.6, 123.7, 110.3, 21.4; MALDI: Mass (m/e) calculated for $\mathrm{C}_{29} \mathrm{H}_{23} \mathrm{~N}$ : 385.5. Found 385.4.

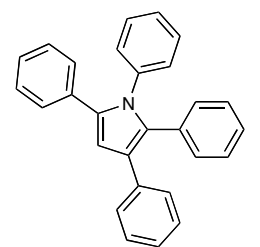

1,2,3,5-tetraphenyl-1-H-pyrrole (9): Purified with $1 \%$ ethyl acetate/hexanes, yielding $67 \mathrm{mg}(66 \%)$ of 9 as a white solid. $\mathrm{R}_{f}=0.88$ (25\% ethyl acetate/hexanes); mp: $200-201{ }^{\circ} \mathrm{C}$ (lit, 200-202 $\left.{ }^{\circ} \mathrm{C}\right) .{ }^{1} \mathrm{H}$ NMR $\left(500 \mathrm{MHz}, \mathrm{CDCl}_{3}\right.$ )

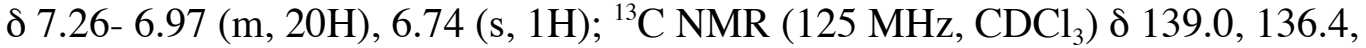
$133.2,132.9,132.4,131.7,129.4,128.8,128.7,128.4,128.2,127.8,127.4$, $126.6,125.7,124.1,123.7,110.2$; All other spectral information are similar to those reported by Stetter and coworkers. ${ }^{6}$

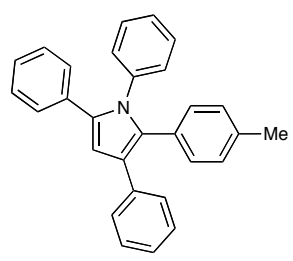

1,3,5-triphenyl-2-p-tolyl-1-H -pyrrole (10): Purified with 2\% ethyl acetate/hexanes, yielding $75 \mathrm{mg}(71 \%)$ of $\mathbf{1 0}$ as a clear oil. $\mathbf{R}_{f}=0.82(25 \%$ ethyl acetate/hexanes); ${ }^{1} \mathrm{H}$ NMR $\left(500 \mathrm{MHz} \mathrm{CDCl}_{3}\right) \delta 7.22-7.05(\mathrm{~m}, 19 \mathrm{H})$, $6.89(\mathrm{~s}, 1 \mathrm{H}), 2.36(\mathrm{~s}, 3 \mathrm{H}) ;{ }^{13} \mathrm{C} \mathrm{NMR}\left(125 \mathrm{MHz}, \mathrm{CDCl}_{3}\right) \delta 139.5,135.8$, $135.0,133.4,133.0,132.8,132.2,131.8,130.0,129.8,129.5,128.9,128.7$, 127.2, 126.1, 125.4, 122.7, 109.2, 20.3; MALDI: Mass (m/e) calculated for $\mathrm{C}_{29} \mathrm{H}_{23} \mathrm{~N}: 385.5$. Found 385.8.

6. Stetter, H.; Schmitz, P.; Schreckenberg, M. Chem. Ber. 1977, 110, 1971-1977. 


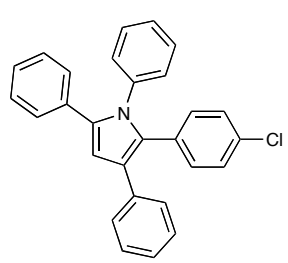

2-(4-chlorophenyl)-1,3,5-triphenyl-1- $\boldsymbol{H}$-pyrrole (11): Purified with 2\% ethyl acetate/hexanes, yielding $68 \mathrm{mg}(61 \%)$ of $\mathbf{1 1}$ as a yellow solid. $\mathbf{R}_{f}=$ 0.61 (25\% ethyl acetate/hexanes); ${ }^{1} \mathrm{H}$ NMR $\left(500 \mathrm{MHz}, \mathrm{CDCl}_{3}\right) \delta$ 7.19-7.02 $(\mathrm{m}, 14 \mathrm{H}), 6.91-6.86(\mathrm{~m}, 5 \mathrm{H}), 6.61(\mathrm{~s}, 1 \mathrm{H}) ;{ }^{13} \mathrm{C} \mathrm{NMR}\left(125 \mathrm{MHz}, \mathrm{CDCl}_{3}\right) \delta$ $138.8,136.1,135.5,133.1,132.9,132.8,131.6,131.4,130.9,129.3,129.0$, $128.8,128.4,127.6,126.8,125.9,124.2,110.4$; All other spectral information are similar to those reported by Stetter and Schreckenberg. ${ }^{7}$

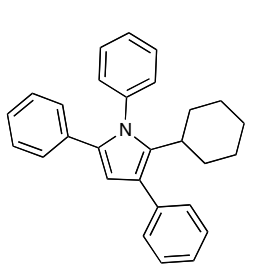

2-cyclohexyl-1, 3, 5-triphenyl-1H-pyrrole (12): Purified with 2\% ethyl acetate/hexanes yielding $71 \mathrm{mg}(69 \%)$ of $\mathbf{1 2}$ as a white solid. $\mathrm{R}_{f}=0.77(25 \%$ ethyl acetate/hexanes); mp: $162-163^{\circ} \mathrm{C}$. IR (film); ${ }^{1} \mathrm{H}$ NMR $\left(500 \mathrm{MHz}, \mathrm{CDCl}_{3}\right)$ $\delta 7.50-7.38(\mathrm{~m}, 8 \mathrm{H}), 7.10-7.08(\mathrm{~m}, 7 \mathrm{H}), 6.40(\mathrm{~s}, 1 \mathrm{H}), 2.61(\mathrm{t}, J=12.1,1 \mathrm{H})$, $1.73-0.90(\mathrm{~m}, 10 \mathrm{H}) ;{ }^{13} \mathrm{C}$ NMR $(125 \mathrm{MHz}) \delta 140.0,138.6,137.3,133.6,130.2$, 130.0, 128.3, 128.2, 126.1, 125.9, 123.2, 111.5, 37.8, 33.5, 27.4, 26.1; MALDI: Mass (m/e) calculated for $\mathrm{C}_{28} \mathrm{H}_{27} \mathrm{~N}$ : 377.5. Found 377.2.

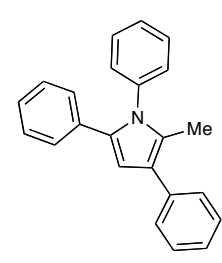

2-methyl-1, 3, 5-triphenyl-1 $\boldsymbol{H}$-pyrrole (13): Purified with 2\% ethyl acetate/hexanes, yielding $42 \mathrm{mg}(71 \%)$ of $\mathbf{1 3}$ as a white solid. $\mathrm{R}_{f}=0.58(25 \%$ ethyl acetate/hexanes); mp: $171-172^{\circ} \mathrm{C}$ (lit, $173-175^{\circ} \mathrm{C}$ ). ${ }^{1} \mathrm{H}$ NMR $(500 \mathrm{MHz}$, $\left.\mathrm{CDCl}_{3}\right) \delta$ 7.55-7.24 (m, 8H), 7.15-7.12 (m, 7H), $6.59(\mathrm{~s}, 1 \mathrm{H}), 2.27(\mathrm{~s}, 3 \mathrm{H}) ;{ }^{13} \mathrm{C}$ NMR $(125 \mathrm{MHz}) \delta 139.5,137.1,134.1,133.4,132.3,129.2,128.9,128.6$, $128.3,128.2,128.1,127.8,126.1,125.7,122.9,109.5,12.7$; All spectral data are similar to those report by Stetter and Schreckenberg. ${ }^{7}$

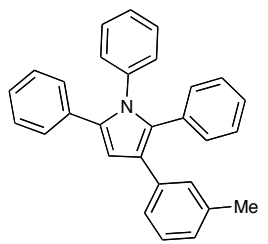

1,2,5-triphenyl-3-m-1 $\boldsymbol{H}$-pyrrole (14): Purified with 2-3\% ethyl acetate/hexanes yielding $65 \mathrm{mg}(62 \%)$ of $\mathbf{1 4}$ as clear oil. $\mathrm{R}_{f}=0.81$ (25\% ethyl acetate/hexanes); ${ }^{1} \mathrm{H}$ NMR $\left(500 \mathrm{MHz}, \mathrm{CDCl}_{3}\right) \delta$ 7.32-7.24 (m, 19H), 6.81(s, $1 \mathrm{H}), 2.45(\mathrm{~s}, 3 \mathrm{H}) ;{ }^{13} \mathrm{C}$ NMR $\left(100 \mathrm{MHz}, \mathrm{CDCl}_{3}\right) \delta 137.8,133.0,133.7,132.2$, $131.9,131.7,130.9,130.5,129.1,128.1,127.9,127.5,127.4,127.0,126.9$, 125.9, 125.3, 122.3, 109.0, 20.2; MALDI: Mass (m/e) calculated for $\mathrm{C}_{29} \mathrm{H}_{23} \mathrm{~N}$ : 385.5. Found 385.7 .

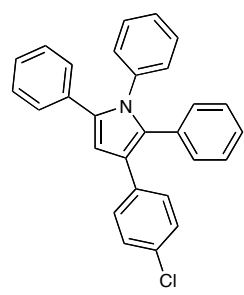

3-(-4-chlorophenyl)-1,2,5-triphenyl-1 $\boldsymbol{H}$-pyrrole (15): Purified with 2-3\% ethyl acetate/hexanes yielding $64 \mathrm{mg}(58 \%)$ of 15 as an oil. $\mathrm{R}_{f}=0.63(25 \%$ ethyl acetate/hexanes); ${ }^{1} \mathrm{H}$ NMR $\left(500 \mathrm{MHz}, \mathrm{CDCl}_{3}\right) \delta 7.17-7.11(\mathrm{~m}, 15 \mathrm{H})$, 7.03-6.98 (m, 4H), $6.68(\mathrm{~s}, 1 \mathrm{H}) ;{ }^{13} \mathrm{C} \mathrm{NMR}\left(100 \mathrm{MHz}, \mathrm{CDCl}_{3}\right) \delta 139.1,136.2$, 135.9 , 131.6, 131.4, 129.8, 129.6, 129.6, 129.3, 128.8, 128.7, 128.5, 128.3, 127.5, 127.4, 126.7, 122.5, 109.9; MALDI: Mass (m/e) calculated for $\mathrm{C}_{28} \mathrm{H}_{20} \mathrm{ClN}$ : 405.9. Found 405.4.

7. Stetter, H.; Schreckenberg, M. Chem. Ber. 1974, 107, 2453-2458. 


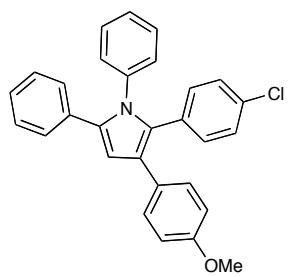

2-(4-chlorophenyl)-3-(4-methoxyphenyl)-1,5-diphenyl-1 $H$-pyrrole (16): Purified with 5\% ethyl acetate/hexanes, yielding $58 \mathrm{mg} \mathrm{(69 \% )} \mathrm{of} \mathbf{1 6}$ as white solid. $\mathrm{R}_{f}=0.55$ (25\% ethyl acetate/hexanes); mp: $189-192^{\circ} \mathrm{C} .{ }^{1} \mathrm{H}$ NMR $(500$ $\left.\mathrm{MHz}, \mathrm{CDCl}_{3}\right) \delta$ 7.21-7.10 (m, 14H), 7.09- $6.79(\mathrm{~m}, 4 \mathrm{H}), 6.64(\mathrm{~s}, 1 \mathrm{H}), 3.80(\mathrm{~s}$, $3 \mathrm{H}) ;{ }^{13} \mathrm{C}$ NMR $(125 \mathrm{MHz}) \delta 158.0,138.9,135.3,133.0,132.9,131.5,129.6$, $129.3,128.9,128.8,128.6,128.4,128.2,127.5,126.7,123.9,114.0,110.4$, 55.4; MALDI: Mass (m/e) calculated for $\mathrm{C}_{29} \mathrm{H}_{22} \mathrm{ClNO}$ : 435.9. Found 435.3.

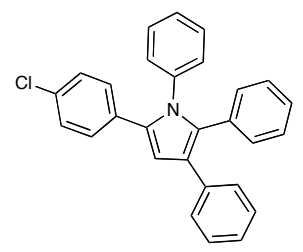

5-(4-chlorophenyl)-1,2,3-triphenyl-1 $\boldsymbol{H}$-pyrrole (17): Purified with 2-3\% ethyl acetate/hexanes, yielding $89 \mathrm{mg}(80 \%)$ of $\mathbf{1 7}$ as a white solid. $\mathrm{R}_{f}=0.68$ (25\% ethyl acetate/hexanes); mp: $198-201{ }^{\circ} \mathrm{C} .{ }^{1} \mathrm{H}$ NMR $\left(500 \mathrm{MHz}, \mathrm{CDCl}_{3}\right) \delta$ 7.29-7.00 (m, 19H), $6.74(\mathrm{~s}, 1 \mathrm{H}) ;{ }^{13} \mathrm{C}$ NMR $(125 \mathrm{MHz}) \delta 138.8,136.2,133.8$, $132.8,132.7,131.7,131.6,129.9,129.3,128.9,128.5,128.4,128.2$, 127.6, 127.4, 125.9, 123.9, 110.5; MALDI: Mass (m/e) calculated for $\mathrm{C}_{28} \mathrm{H}_{20} \mathrm{ClN}$ : 405.9. Found 405.0.

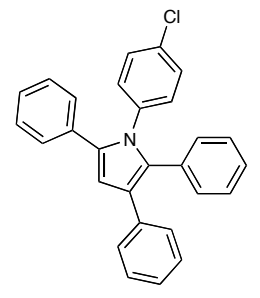

1-(4-Chlorophenyl)-2,3,5-triphenyl-1-H-pyrrole (18): Purified with $2 \%$ ethyl acetate/hexanes, yielding $48 \mathrm{mg}(57 \%)$ of $\mathbf{1 8}$ as a yellow oil. $\mathbf{R}_{f}=0.61(25 \%$ ethyl acetate/hexanes). ${ }^{1} \mathrm{H} \mathrm{NMR}\left(500 \mathrm{MHz}, \mathrm{CDCl}_{3}\right) \delta$ 7.24-6.91 (m, 19H), 6.71 $(\mathrm{s}, 1 \mathrm{H}) ;{ }^{13} \mathrm{C} \mathrm{NMR}\left(125 \mathrm{MHz}, \mathrm{CDCl}_{3}\right) \delta 137.3,134.6,132.2,131.3,131.2,130.9$, 130.1 , 128.4, 127.7, 127.4, 126.9, 126.8, 126.6, 126.0, 125.8, 124.3, 122.3, 108.9; MALDI: Mass (m/e) calculated for $\mathrm{C}_{28} \mathrm{H}_{20} \mathrm{ClN}$ : 405.9. Found 405.1.

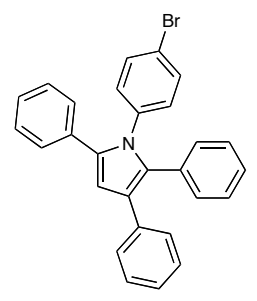

1-(4-bromophenyl)-2,3,5-triphenyl-1- $\boldsymbol{H}$-pyrrole (19): Purified with $2 \%$ ethyl acetate/hexanes, yielding $62 \mathrm{mg}(71 \%)$ of 19 as a white solid. $\mathrm{R}_{f}=0.58(25 \%$ ethyl acetate/hexanes); mp: $173-176^{\circ} \mathrm{C}$. IR (film) 3056, 3030, 1601, 1489, 1373 ;

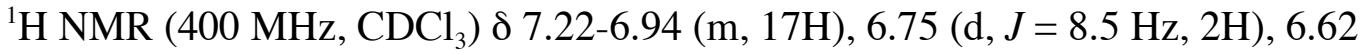
$(\mathrm{s}, 1 \mathrm{H}) ;{ }^{13} \mathrm{C} \mathrm{NMR}\left(100 \mathrm{MHz}, \mathrm{CDCl}_{3}\right) \delta 138.1,136.0,134.9,132.8,132.5,131.9$, 131.7, 130.7, 128.9, 128.4, 128.3, 127.4, 126.8, 125.8, 121.1, 110.6; MALDI: Mass (m/e) calculated for $\mathrm{C}_{28} \mathrm{H}_{20} \mathrm{BrN}$ : 450.4. Found 450.9 .

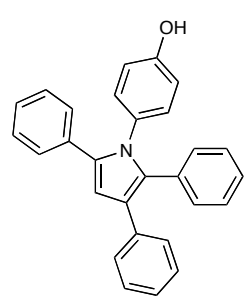

4-(2,3,5-triphenyl-1H -pyrrol-1yl)-phenol (20): Purified with $15 \%$ ethyl acetate/hexanes, yielding $65 \mathrm{mg}(61 \%)$ of $\mathbf{2 0}$ as oil. $\mathbf{R}_{f}=0.32(25 \%$ ethyl acetate/hexanes); IR (film) 3394, 2962, 1598, 1513, $1261 \mathrm{~cm}^{-1} ;{ }^{1} \mathrm{H}$ NMR (500 $\left.\mathrm{MHz}, \mathrm{CDCl}_{3}\right) \delta$ 7.27- $7.14(\mathrm{~m}, 15 \mathrm{H}), 6.86(\mathrm{~m}, 2 \mathrm{H}), 6.70(\mathrm{~s}, 1 \mathrm{H}), 6.63(\mathrm{~m}, 2 \mathrm{H})$, 4.71 (bs, $1 \mathrm{H}) ;{ }^{13} \mathrm{C}$ NMR $(125 \mathrm{MHz}) \delta 154.6,136.4,135.1,133.2,133.0,132.6$, $132.2,131.8,130.5,128.8,128.4,128.2,128.1,127.2,126.6,125.7,123.5$, 115.5, 109.9; MALDI: Mass (m/e) calculated for $\mathrm{C}_{28} \mathrm{H}_{21} \mathrm{NO}$ : 387.4. Found 387.1. 


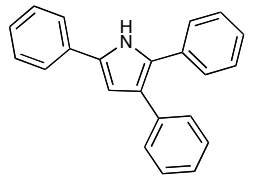

2,3,5-triphenyl-1H-pyrrole (21): Purified with $10 \%$ ethyl acetate/hexanes, yielding $50 \mathrm{mg}(62 \%)$ of $\mathbf{2 1}$ as a white solid. $\mathrm{R}_{f}=0.45$ (25\% ethyl acetate/hexanes); mp $134-135^{\circ} \mathrm{C}$ (lit. $\left.135-137^{\circ} \mathrm{C}\right) .{ }^{1} \mathrm{H}$ NMR $\left(500 \mathrm{MHz}, \mathrm{CDCl}_{3}\right.$ ) $\delta 8.36(\mathrm{~s}, 1 \mathrm{H}), 7.50(\mathrm{~m}, 2 \mathrm{H}), 7.38-7.10(\mathrm{~m}, 13 \mathrm{H}), 6.70(\mathrm{~s}, 1 \mathrm{H}) ;{ }^{13} \mathrm{C}$ NMR $(125$ $\mathrm{MHz}) \delta 136.5,132.9,132.1,129.1,128.9,128.6,128.4,128.2,127.7,126.9$, $126.0,125.8,122.9,108.2$; All other spectral information are similar to those reported by Fürstner and coworkers. ${ }^{8}$

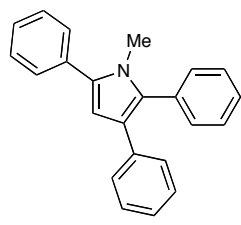

1-methyl-2,3,5-triphenyl-1-H -pyrrole (22): Purified with 2\% ethyl acetate/hexanes, yielding $59 \mathrm{mg}(70 \%)$ of $\mathbf{2 2}$ as a white solid. $\mathrm{R}_{f}=0.73$ (25\%ethyl acetate/hexanes); Mp: $181-183^{\circ} \mathrm{C}$ (lit. $\left.{ }^{9} 178-179^{\circ} \mathrm{C}\right) .{ }^{1} \mathrm{H}$ NMR $(500$ $\mathrm{MHz}_{\mathrm{CDCl}}$ ) $\mathrm{C}_{7.53-7.19}(\mathrm{~m}, 15 \mathrm{H}), 6.51(\mathrm{~s}, 1 \mathrm{H}), 3.50(\mathrm{~s}, 3 \mathrm{H}) ;{ }^{13} \mathrm{C}$ NMR $(125$ $\left.\mathrm{MHz}, \mathrm{CDCl}_{3}\right) \delta 136.6,135.9,133.6,131.3,130.2,129.1,128.8,128.3,128.1$, $127.8,127.2,125.4,122.0,109.0,34.0$; All spectral information are similar to those reported by Horspool and coworkers. ${ }^{10}$

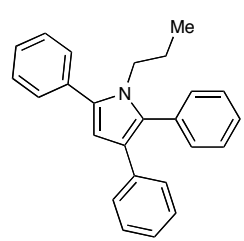

2,3,5-triphenyl-1-propyl-1-H-pyrrole (23): Purified with 1-3\% ethyl acetate/hexanes, yielding $76 \mathrm{mg}(82 \%)$ of as a white solid. $\mathrm{R}_{f}=0.72(25 \%$ ethyl acetate/hexanes); mp: $123-124^{\circ} \mathrm{C} .{ }^{1} \mathrm{H}$ NMR $\left(500 \mathrm{MHz}, \mathrm{CDCl}_{3}\right) \delta$ 7.56-7.37 (m, $9 \mathrm{H}), 7.23-7.11(\mathrm{~m}, 6 \mathrm{H}), 6.51(\mathrm{~s}, 1 \mathrm{H}), 3.93(\mathrm{t}, J=7.3,2 \mathrm{H}), 1.30-1.27(\mathrm{~m}, 2 \mathrm{H})$, $0.51(\mathrm{t}, J=7.3 \mathrm{~Hz}, 3 \mathrm{H}) ;{ }^{13} \mathrm{C} \mathrm{NMR}\left(125 \mathrm{MHz}, \mathrm{CDCl}_{3}\right) \delta 136.7,135.4,134.3$, $133.8,132.3,131.5,129.3,128.8,128.7,128.3,128.0,127.8,127.3,125.3$, 123.1, 109.7, 46.8, 24.4, 11.1; All additional spectral information are similar to those reported by Namy and Farcas. ${ }^{11}$

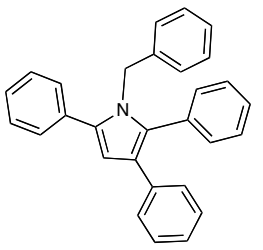

1-benzyl-2,3,5-triphenyl-1-H -pyrrole (24): Purified with $2 \%$ ethyl acetate/hexanes yielding $78 \mathrm{mg}(65 \%)$ of $\mathbf{2 4}$ white solid. $\mathrm{R}_{f}=0.57$ (25\% ethyl acetate/hexanes); mp: $162-165^{\circ} \mathrm{C}$ (lit. $\left.165-167^{\circ} \mathrm{C}\right) .{ }^{1} \mathrm{H} \mathrm{NMR}\left(500 \mathrm{MHz}, \mathrm{CDCl}_{3}\right.$ ) $\delta$ 7.45-7.12 (m, 18H), 6.69-6.68 (m, 2H), $6.61(\mathrm{~s}, 1 \mathrm{H}), 5.13(\mathrm{~s}, 2 \mathrm{H}) ;{ }^{13} \mathrm{C} \mathrm{NMR}$ $\left(125 \mathrm{MHz}, \mathrm{CDCl}_{3}\right) \delta 139.4,136.4,135.8,133.7,133.4,132.6,131.6,129.3$, $128.7,128.6,128.5,128.3,127.9,127.8,127.4,126.3,125.4,123.5,109.7,48.7$; All additional spectral information are similar to those reported by Yoshia and coworkers. ${ }^{12}$

8. Fürstner, A.; Weintritt, H.; Hupperts, A. J. Org. Chem. 1995, 60, 6637-6641.

9 Huisgen, R.; Gotthardt, H.; Bayer, O.; Schaefer, F. Angew. Chem. Int. Ed. 1964, 3, 136.

10. Armesto, D.; Horspool, W.; Ortiz, M.; Romano, S. J. Chem. Soc., Perkin Trans. 1 1992, 171-176.

11. Namy, J.; Farcas, S. Tetrahedron 2001, 57, 4881-4888.

12. Yoshida, H.; Utsumi, F.; Suzuki, H.; Ito, S.; Sakashita, S.; Ogata, T.; Matsumoto, K. Bull Chem. Soc. Jpn. 1992,

$65,698-702$. 


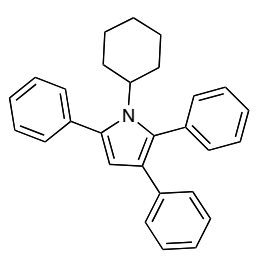

1-cyclohexyl-2,3,5-triphenyl-1H -pyrrole (25): Purified with $2 \%$ ether/hexanes, yielding $66 \mathrm{mg}(64 \%)$ of $\mathbf{2 5}$ as a white solid. $\mathrm{R}_{f}=0.75(25 \%$ ethyl acetate/hexanes); mp: $165-167^{\circ} \mathrm{C} .{ }^{1} \mathrm{H}$ NMR $\left(500 \mathrm{MHz}, \mathrm{CDCl}_{3}\right) \delta 7.51-$ $7.39(\mathrm{~m}, 9 \mathrm{H}), 7.13-7.03(\mathrm{~m}, 6 \mathrm{H}), 6.39(\mathrm{~s}, 1 \mathrm{H}), 3.94(\mathrm{~m}, 1 \mathrm{H}), 1.86(\mathrm{~d}, J=11.2$ $\mathrm{Hz}, 2 \mathrm{H}), 1.61-0.72(\mathrm{~m}, 8 \mathrm{H}) ;{ }^{13} \mathrm{C}$ NMR (125 MHz) $\delta 136.7,135.2,134.8,132.6$, 131.7, 130.6, 128.4, 128.2, 128.1, 127.7, 127.5, 125.0, 123.0, 109.9, 58.9, 34.4, 26.7, 25.5; MALDI: Mass (m/e) calculated for $\mathrm{C}_{28} \mathrm{H}_{27} \mathrm{~N}$ : 377.5. Found 377.1.

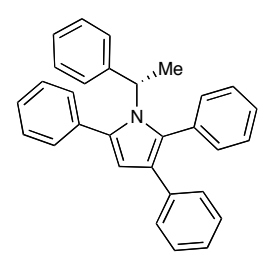

2,3,5-triphenyl-1-((S)-1-phenylethyl)-1- $\boldsymbol{H}$-pyrrole (26): Purified with 5\% ether/hexanes, yielding $60 \mathrm{mg}(55 \%)$ of $\mathbf{2 6}$ as yellow oil. $\mathrm{R}_{f}=0.71$ (25\% ethyl acetate/hexanes); ${ }^{1} \mathrm{H}$ NMR $\left(500 \mathrm{MHz}, \mathrm{CDCl}_{3}\right) \delta$ 7.29-7.06 (m, 18H), 7.05-6.91 $(\mathrm{m}, 2 \mathrm{H}), 6.50(\mathrm{~s}, 1 \mathrm{H}), 5.52(\mathrm{q}, J=5.9 \mathrm{~Hz}, 1 \mathrm{H}), 1.58(\mathrm{~d}, J=7.2 \mathrm{~Hz}, 3 \mathrm{H}) ;{ }^{13} \mathrm{C}$ NMR $(125 \mathrm{MHz}) \delta 143.4,136.5,135.6,134.5,134.2,132.5,131.8,130.5$, $128.4,128.3,128.2,127.9,127.6,127.5,127.0,126.5,125.2,123.2,109.8$, 54.0, 20.0; MALDI: Mass (m/e) calculated for $\mathrm{C}_{30} \mathrm{H}_{25} \mathrm{~N}$ : 399.5. Found 399.2.

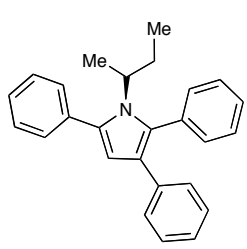

(R)-1-sec-butyl-2,3,5-triphenyl-1H -pyrrole (27): Purified with 2\% ether/hexanes, yielding $54 \mathrm{mg}(56 \%)$ of 27 as a yellow oil. $\mathrm{R}_{f}=0.70$ (25\% ethyl acetate/hexanes); ${ }^{1} \mathrm{H}$ NMR $\left(500 \mathrm{MHz}, \mathrm{CDCl}_{3}\right) \delta$ 7.50-7.36 (m, 10H), 7.127.03(m, 5H), $6.38(\mathrm{~s}, 1 \mathrm{H}), 4.10(\mathrm{~m}, 1 \mathrm{H}), 1.55(\mathrm{~m}, 1 \mathrm{H}), 1.37-1.35(\mathrm{~m}, 1 \mathrm{H}), 1.32(\mathrm{~d}$, $J=7.1 \mathrm{~Hz}, 3 \mathrm{H}), 0.62(\mathrm{t}, J=7.3 \mathrm{~Hz}, 3 \mathrm{H}) ;{ }^{13} \mathrm{C} \mathrm{NMR}(125 \mathrm{MHz}) \delta 136.7,135.3$, 134.8, 132.5, 130.6, 128.5, 128.2, 128.1, 128.0, 127.7, 127.5, 125.0, 109.9, 55.6, 30.2, 22.8, 11.3; MALDI: Mass (m/e) calculated for $\mathrm{C}_{26} \mathrm{H}_{25} \mathrm{~N}$ : 351.4 Found 351.4.

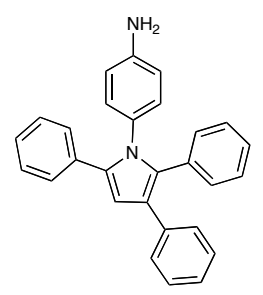

4-(2,3,5-triphenyl-1H-pyrrol-1-yl)benzeneamine (28): Purified with $20 \%$ ethyl acetate/hexanes to give $37 \mathrm{mg}(70 \%)$ of $\mathbf{2 8}$ as an oil. $\mathbf{R}_{f}=0.41$ (25\% ethyl acetate/hexanes); IR (film) 3468, 3378, 3054, 2916, 2848, 1621, 1600, 1515 $\mathrm{cm}^{-1}$; ${ }^{1} \mathrm{H}$ NMR $\left(500 \mathrm{MHz}, \mathrm{CDCl}_{3}\right) \delta$ 7.37-7.13 (m, 15H), $6.78(\mathrm{~m}, 2 \mathrm{H}), 6.69(\mathrm{~s}$, $1 \mathrm{H}), 6.48(\mathrm{~m}, 2 \mathrm{H}) ;{ }^{13} \mathrm{C} \mathrm{NMR}(125 \mathrm{MHz}) \delta 145.2,136.6,135.1,133.3,131.8$, $130.1,128.8,128.6,128.4,128.3,128.0,127.0,126.4,125.6,123.3,116.6$, 115.1, 109.7; MALDI: Mass (m/e) calculated for $\mathrm{C}_{29} \mathrm{H}_{22} \mathrm{~N}_{2}$ : 386.5. Found

386.6 .

\section{Procedure for Microwave Reaction (compound 6):}

A conical test tube was charged with the thiazolium salt ( $14 \mathrm{mg}, 0.055 \mathrm{mmol}, 0.20$ equiv). To the conical tube, benzoyltrimethylsilane (100 $\mathrm{mg}, 0.55 \mathrm{mmol}, 2.0$ equiv) in THF $(0.25 \mathrm{~mL})$ was added by syringe to the test tube followed by the addition of DBU $(13 \mu \mathrm{L}, 0.083 \mathrm{mmol}, 0.30$ equiv). To reaction mixture chalcone ( $61 \mathrm{mg}, 0.275 \mathrm{mmol}, 1.0$ equiv) in THF $(0.25 \mathrm{~mL})$ was added by syringe followed by the addition of 2 -propanol ( $83 \mu \mathrm{L}, 1.10 \mathrm{mmol}, 4.0$ equiv). The conical tube was capped with septa and crimped aluminum collar and heated for 15 minutes in the microwave at $160{ }^{\circ} \mathrm{C}$. After this first heating cycle, the septa was removed and a solution of amine (77 mg, $0.825 \mathrm{mmol}, 3.0$ equiv) followed by $p$-toluenesulfonic acid (104 $\mathrm{mg}, 0.55 \mathrm{mmol}$, 2.0 equiv) in ethanol $(0.5 \mathrm{~mL})$ and $4 \AA$ molecular sieves (spatula tip) were added to the reaction mixture and heated in the microwave for an additional 15 minutes at $160{ }^{\circ} \mathrm{C}$. Upon cooling to 
room temperature, the reaction mixture was diluted with ethyl acetate $(30 \mathrm{~mL})$ and washed with water $(10 \mathrm{~mL})$. The aqueous layer was washed with ethyl acetate $(3 \mathrm{X} 30 \mathrm{~mL})$ and the combined the organic extracts were washed with brine $(10 \mathrm{~mL})$ and dried over sodium sulfate, filtered, and concentrated in vacuo. The resulting residue was purified by flash column chromatography on silica gel (2\% ethyl acetate/hexanes) to give $58 \mathrm{mg}(55 \%)$ of $\mathbf{6}$ as a white solid. 
Selected NMR $\left({ }^{1} \mathrm{H}\right.$ and $\left.{ }^{13} \mathrm{C}\right)$ Spectra:
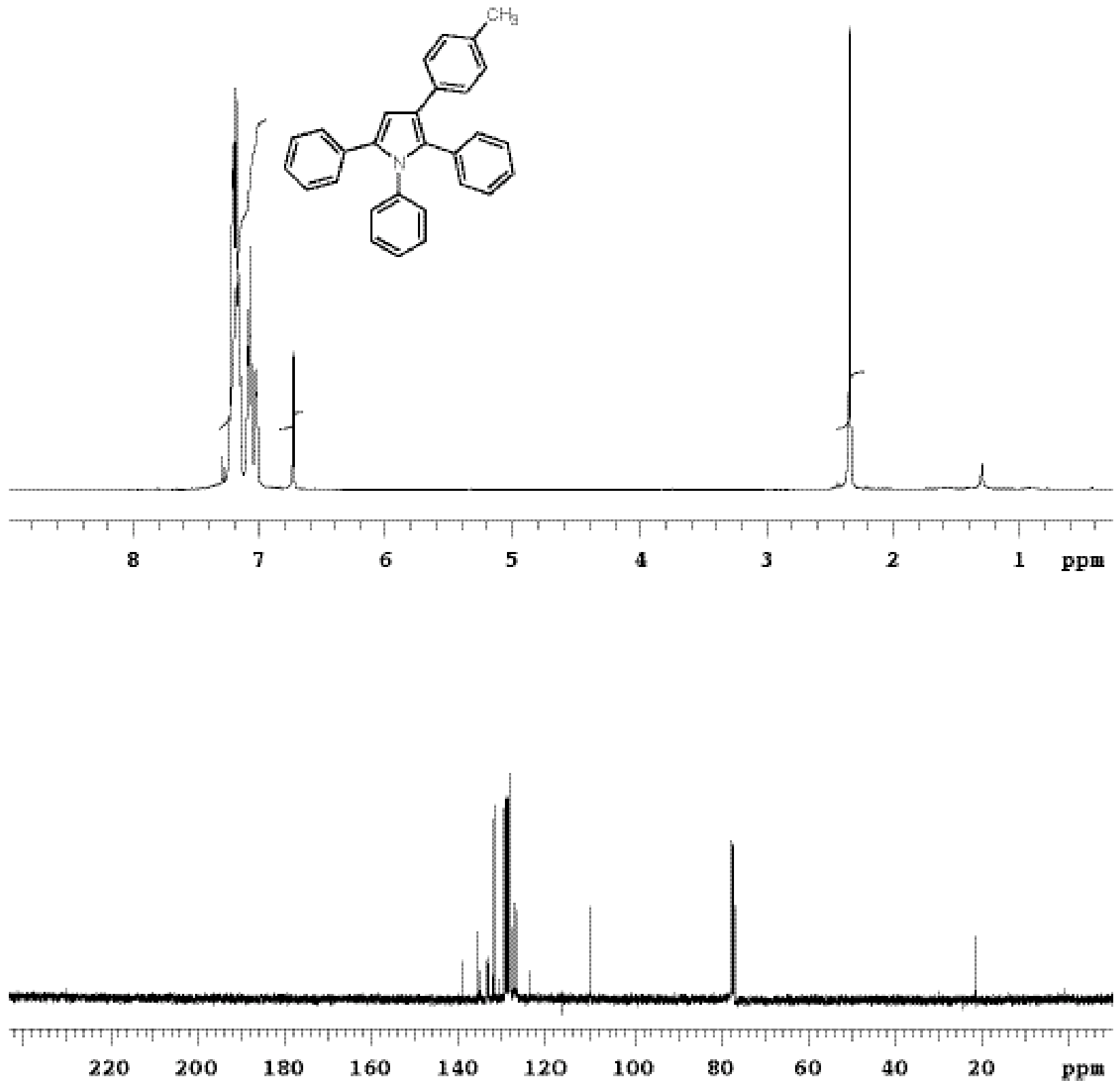

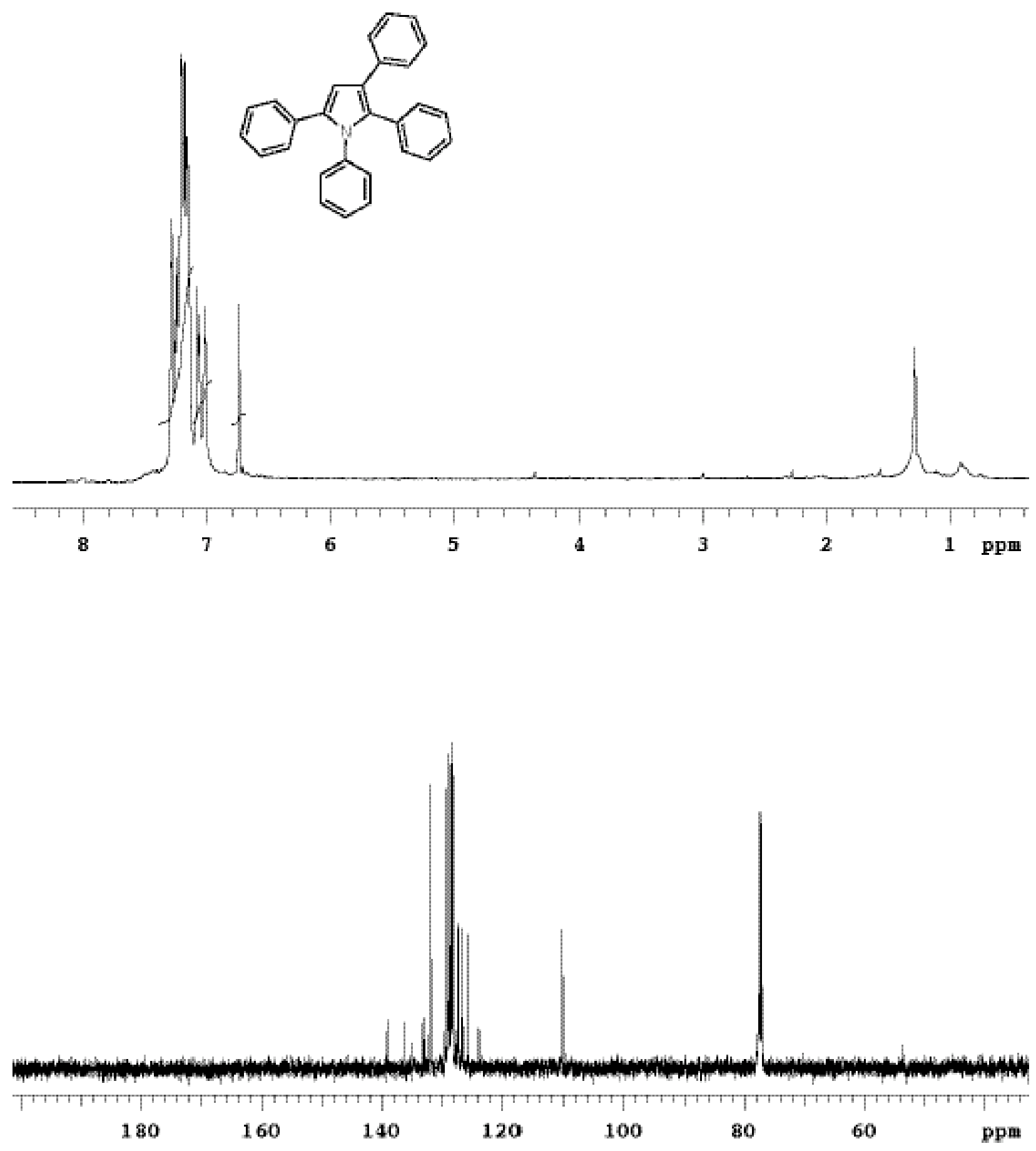

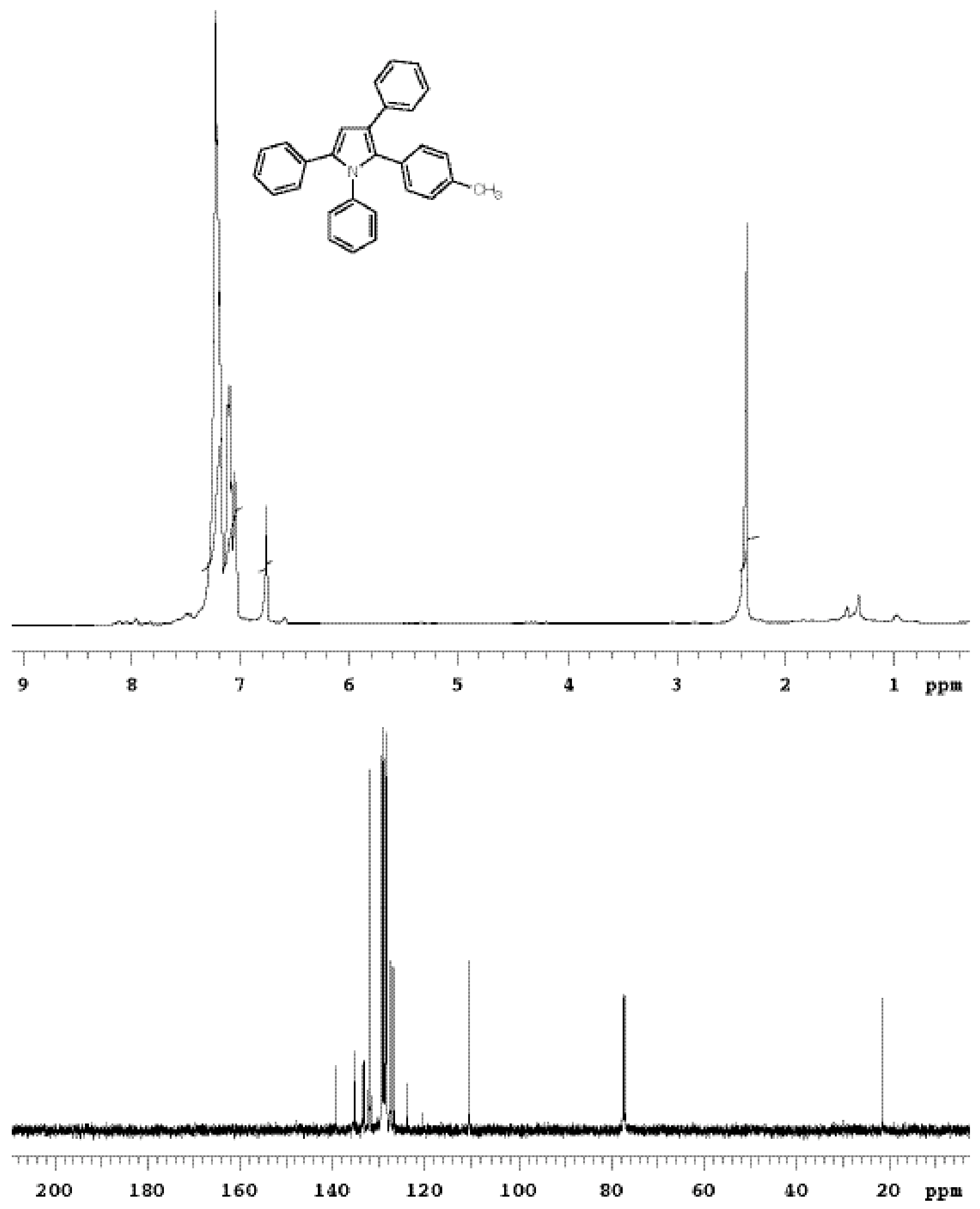


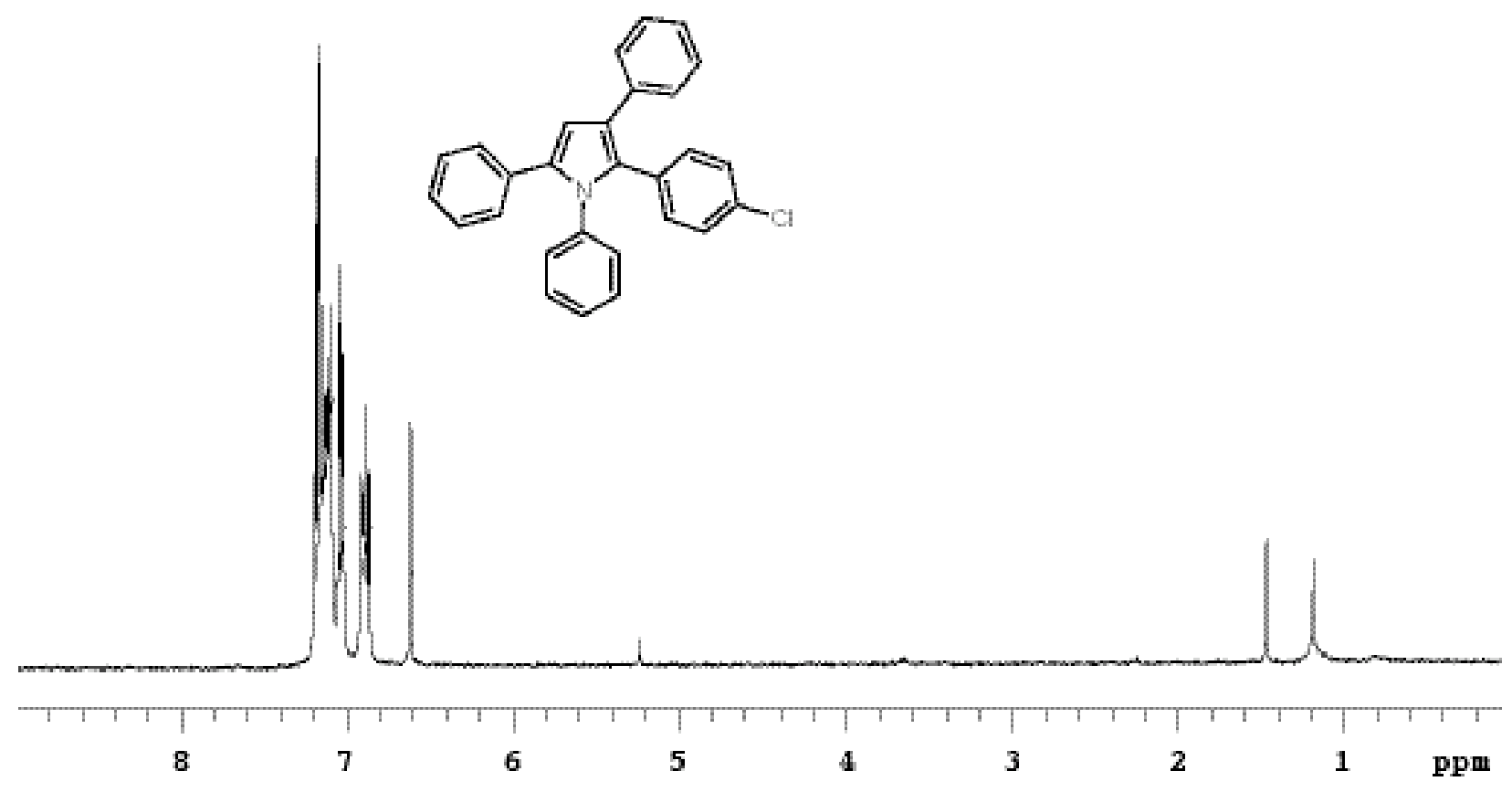



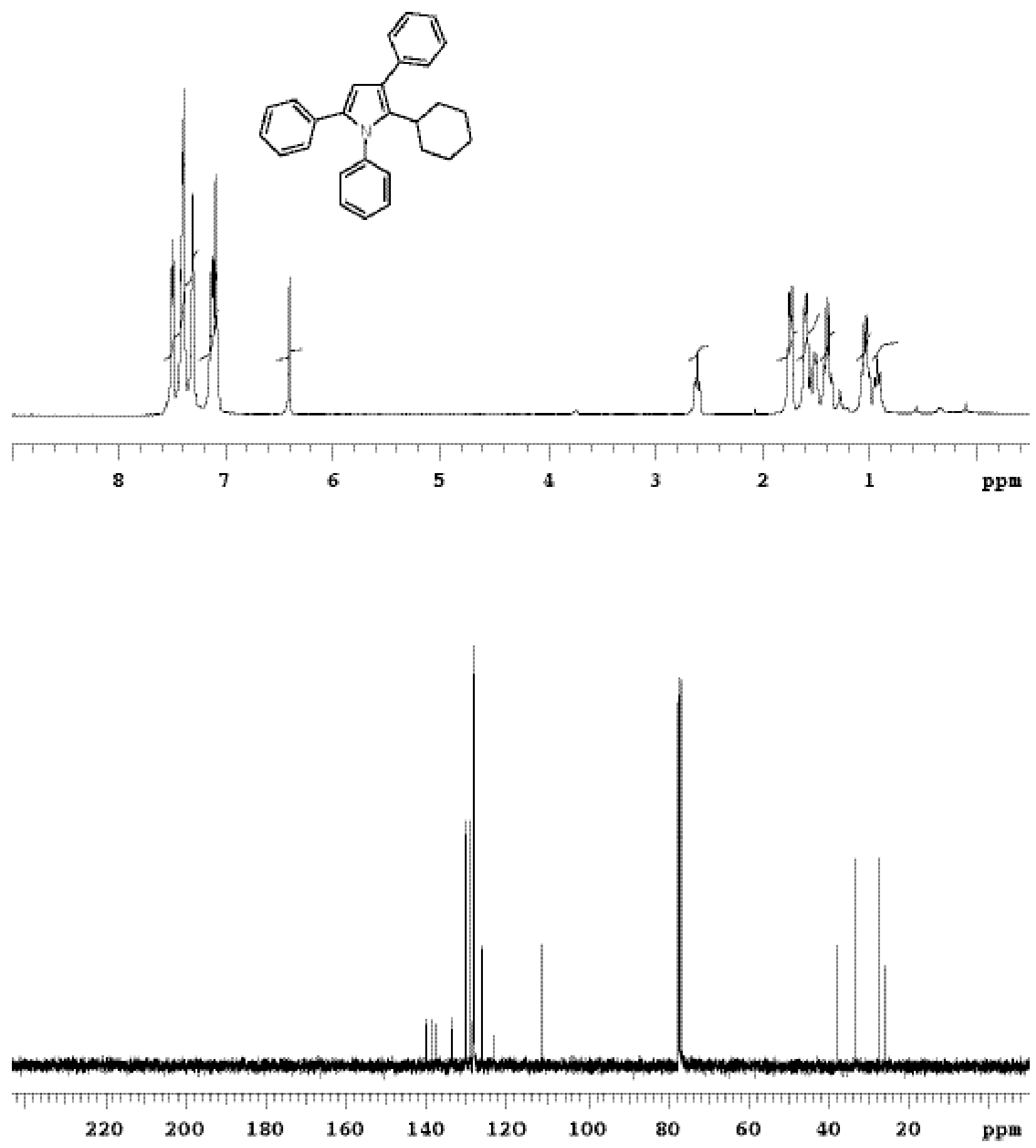

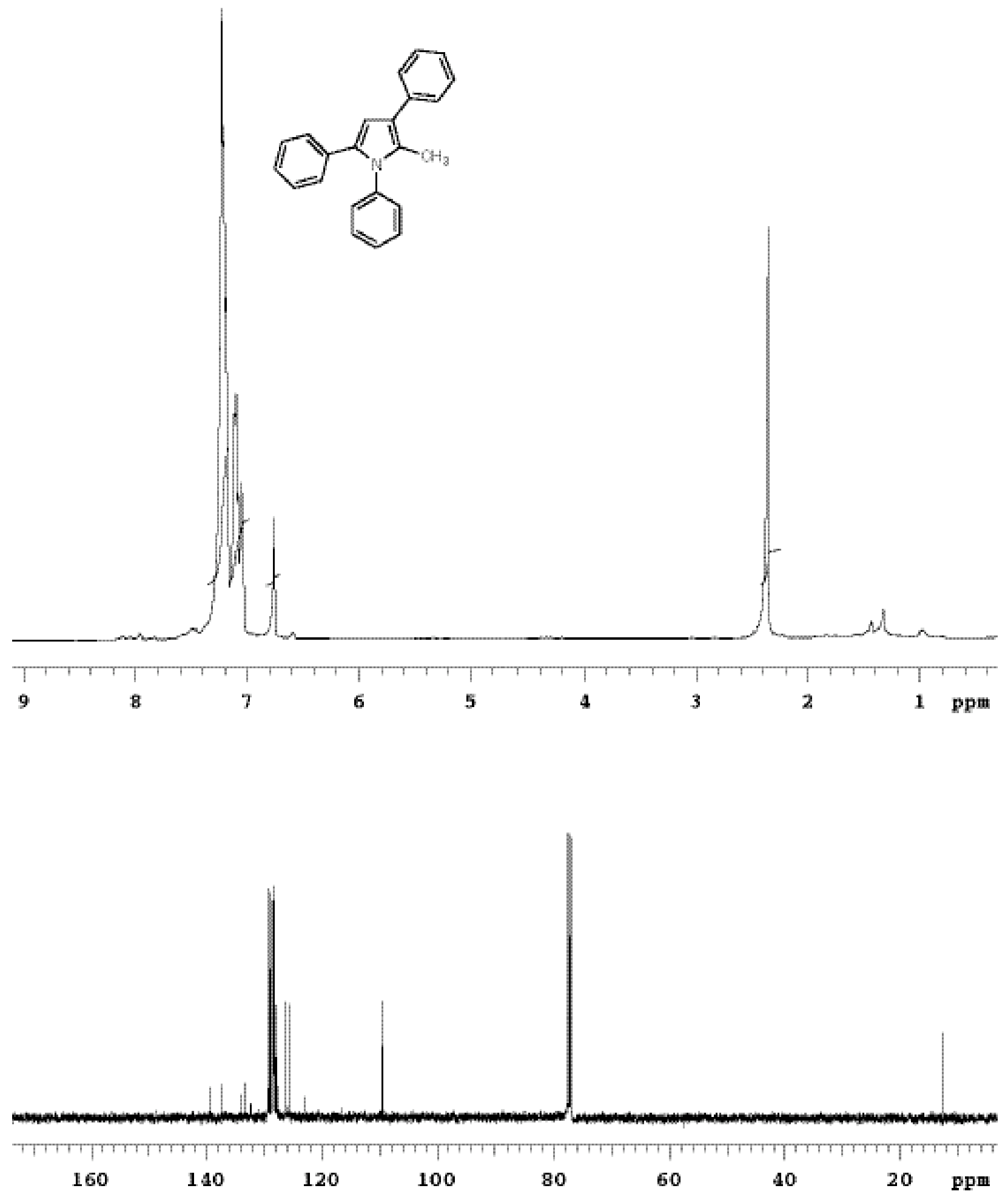
<smiles>Cc1cccc(-c2cc(-c3ccccc3)n(-c3ccccc3)c2-c2ccccc2)c1</smiles>
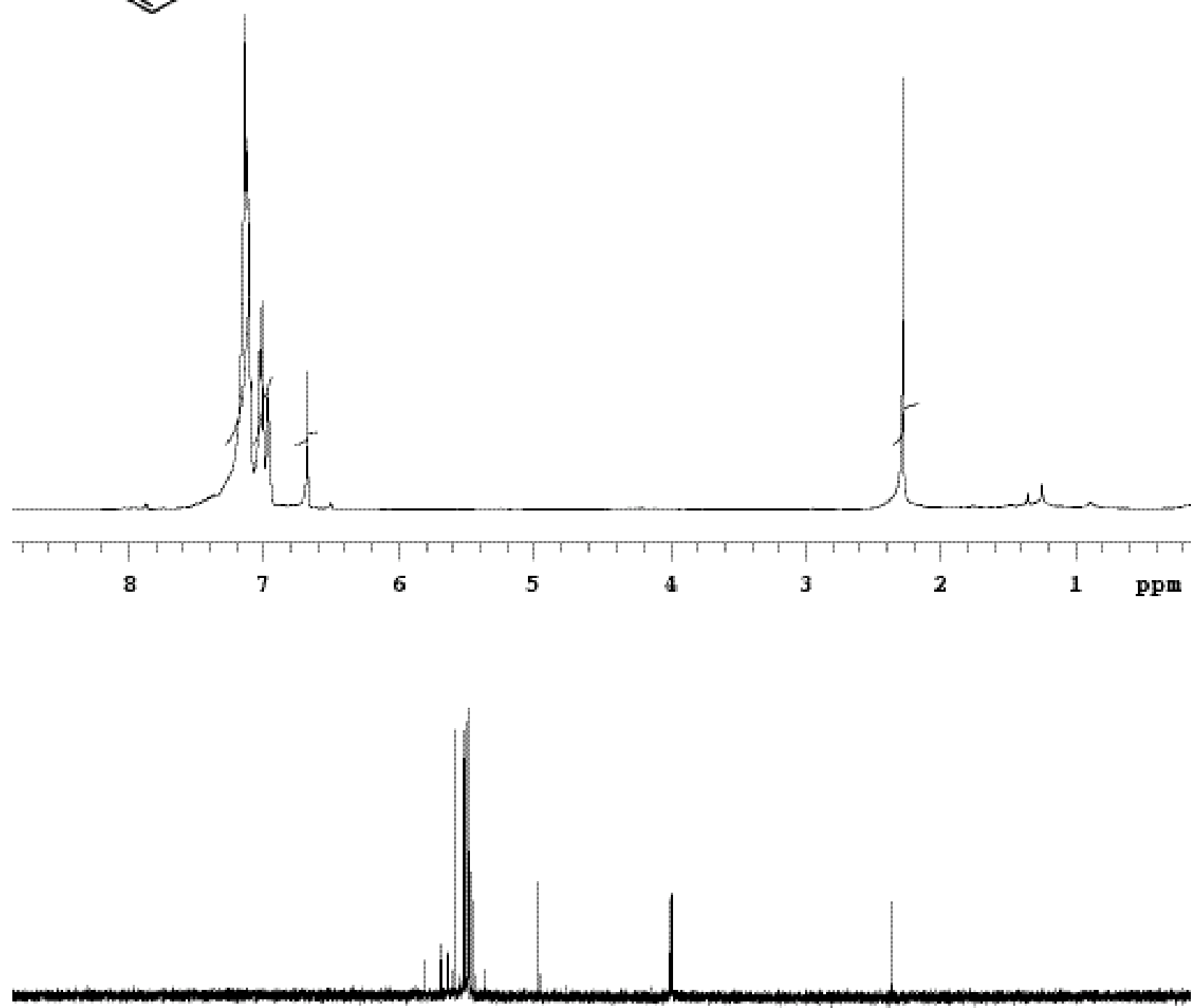

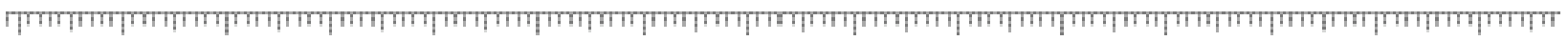

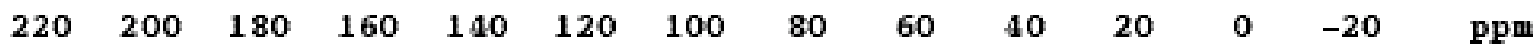




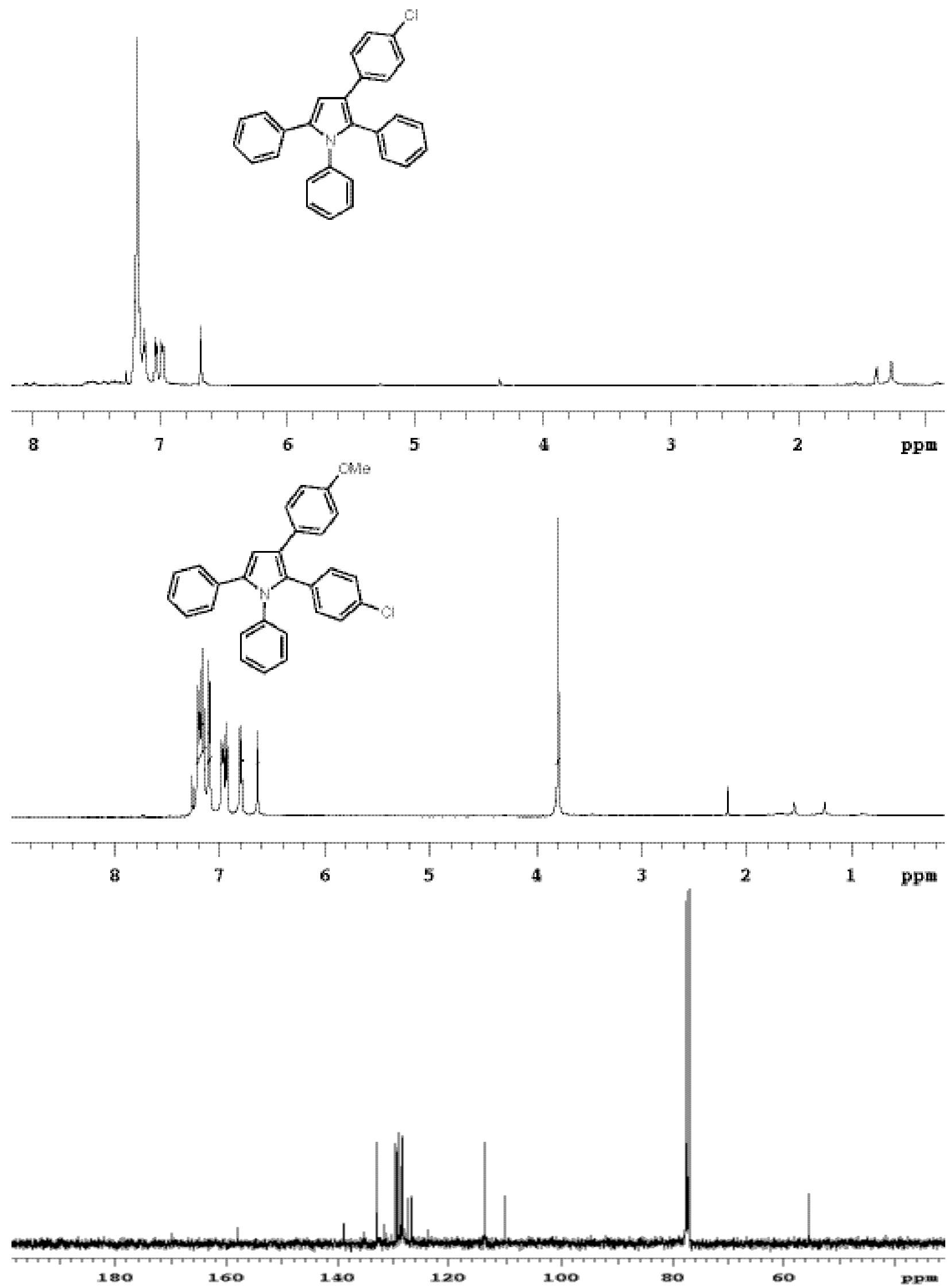



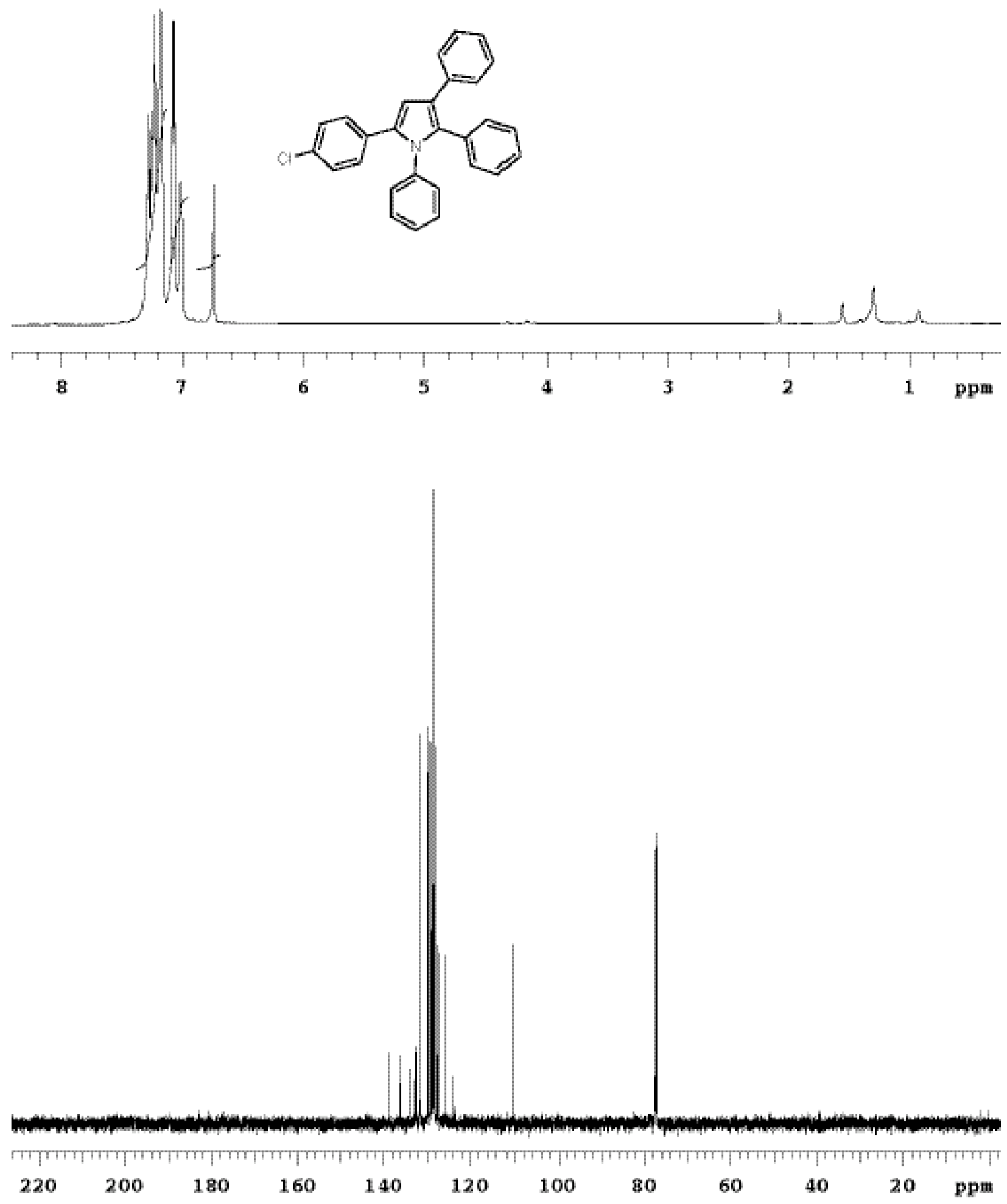

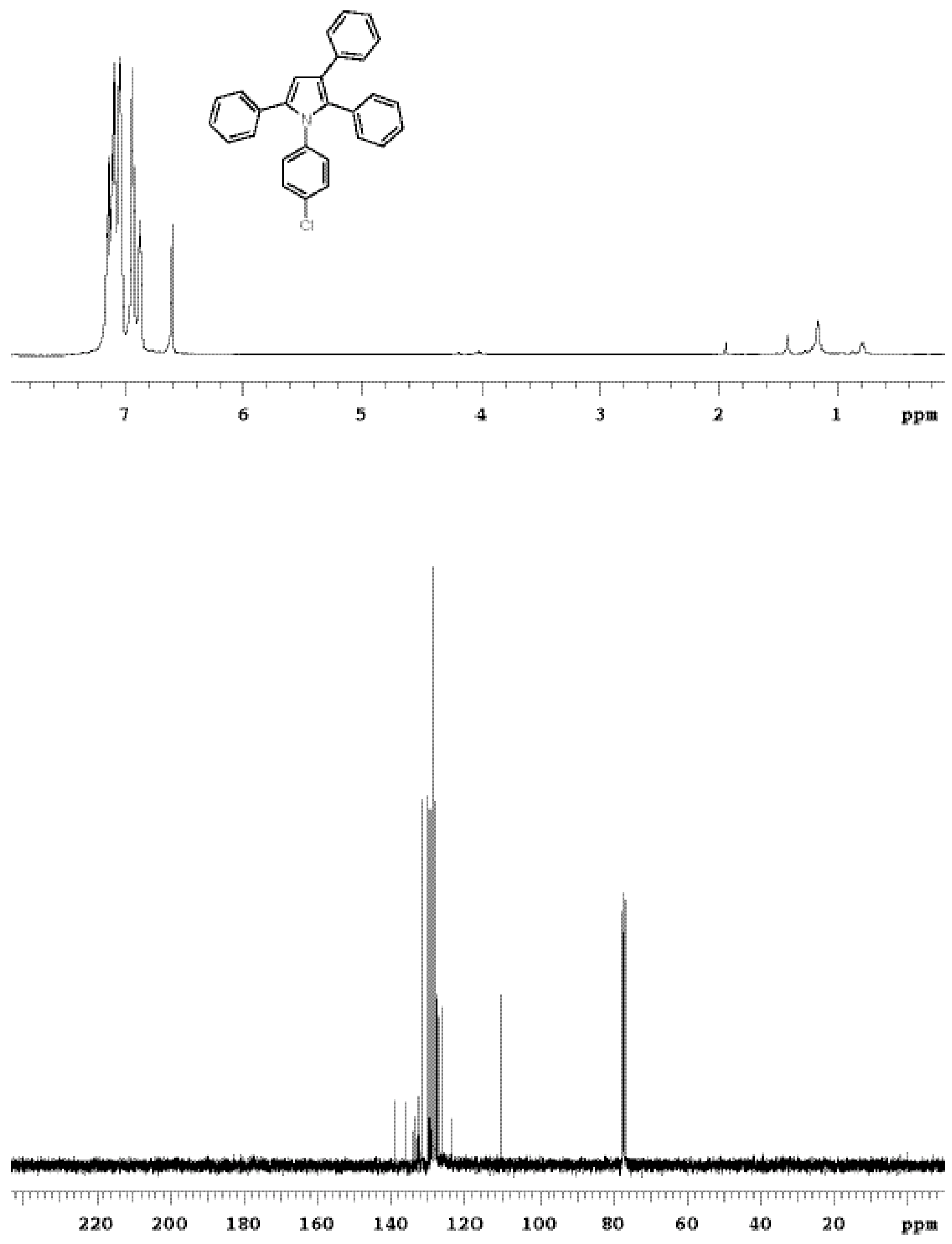

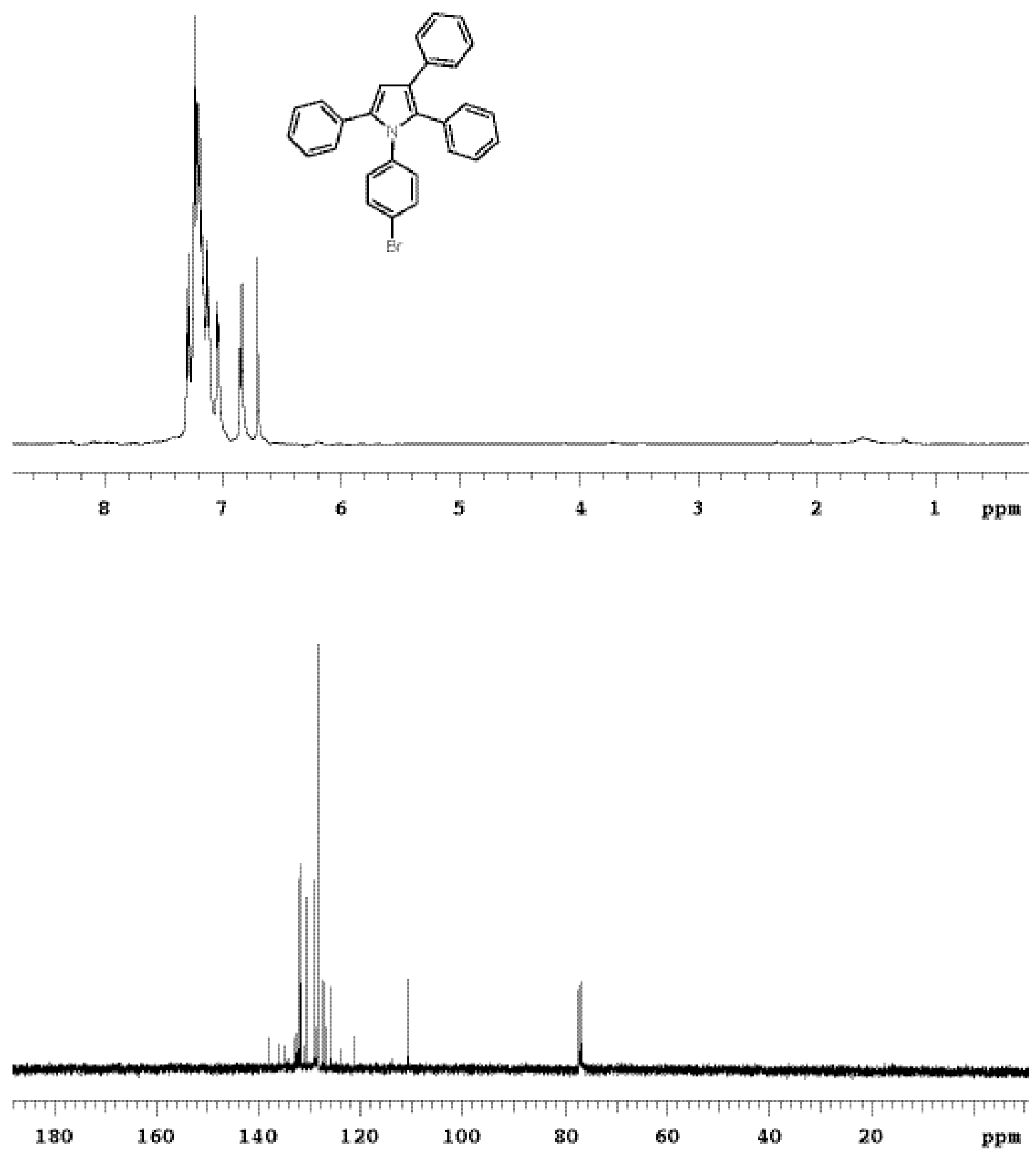

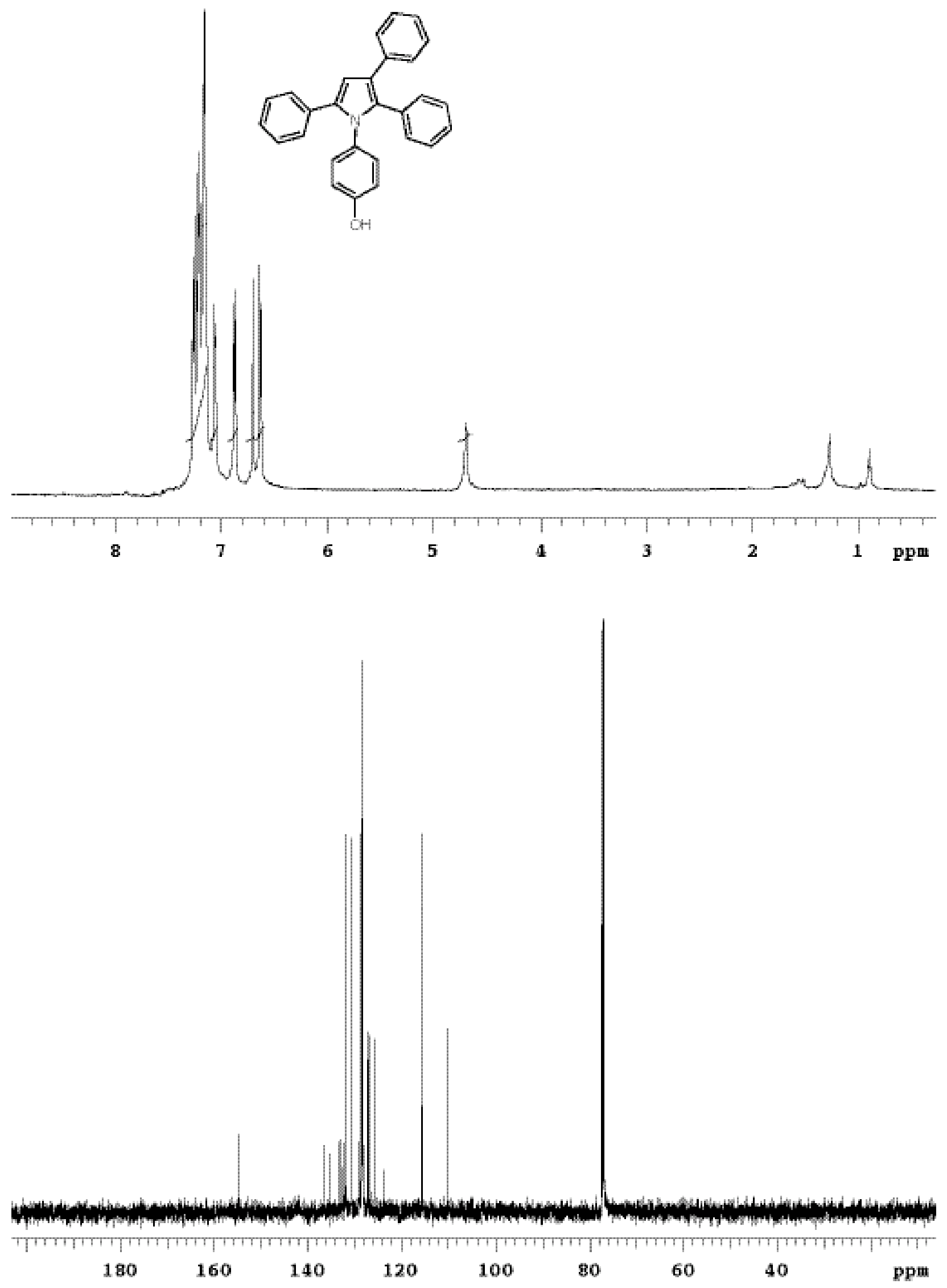

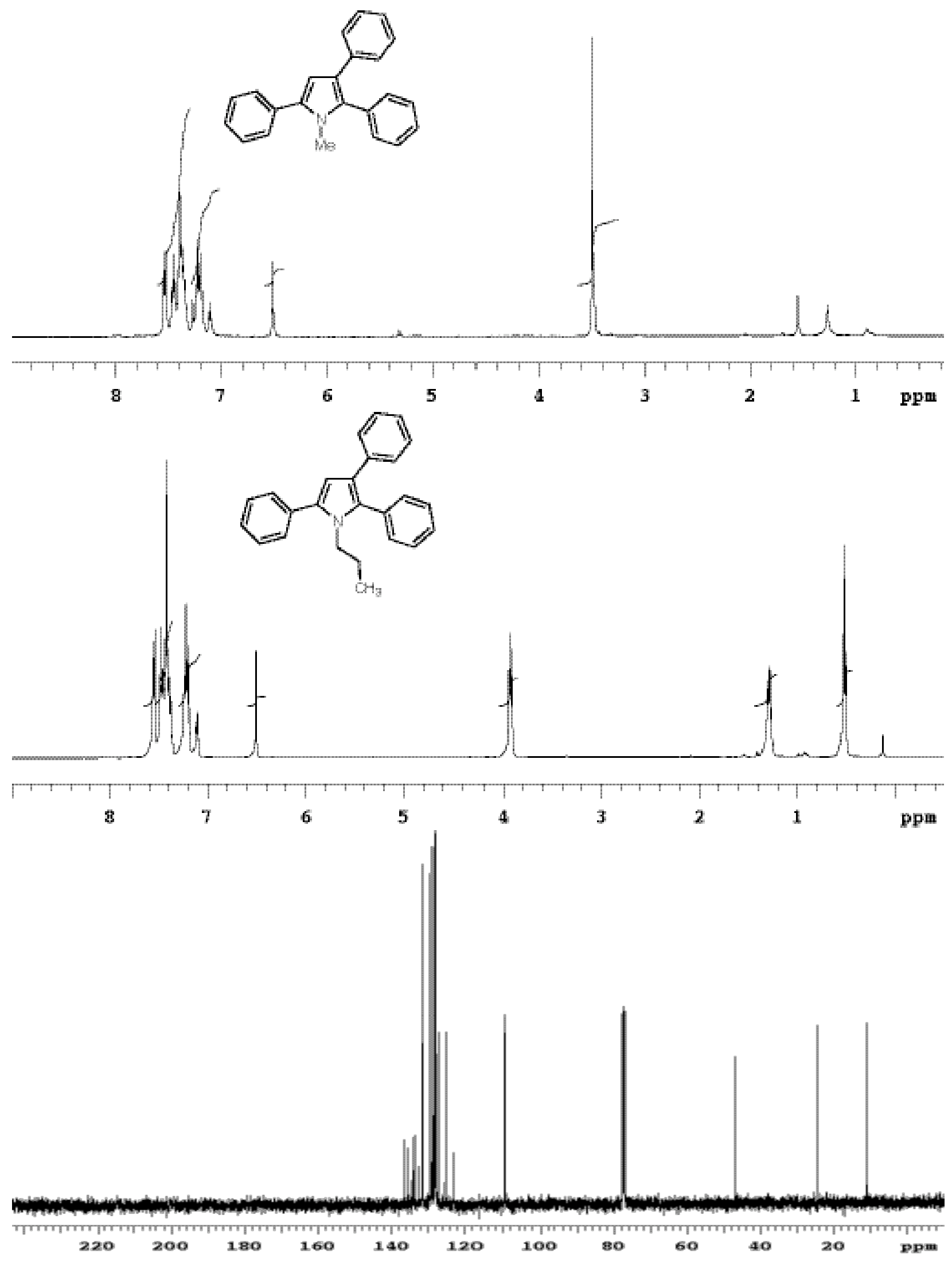

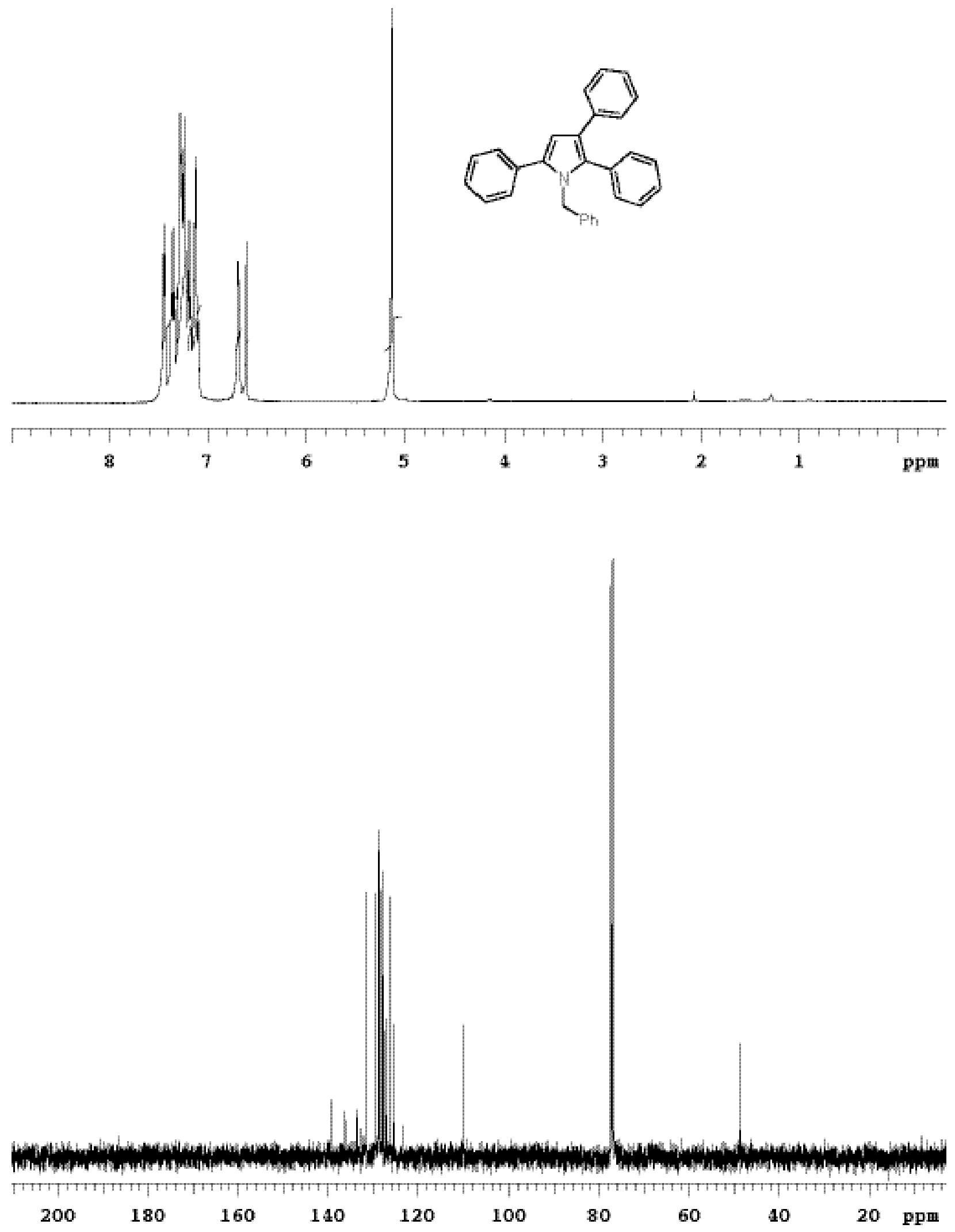
Org. Lett. Supporting Information

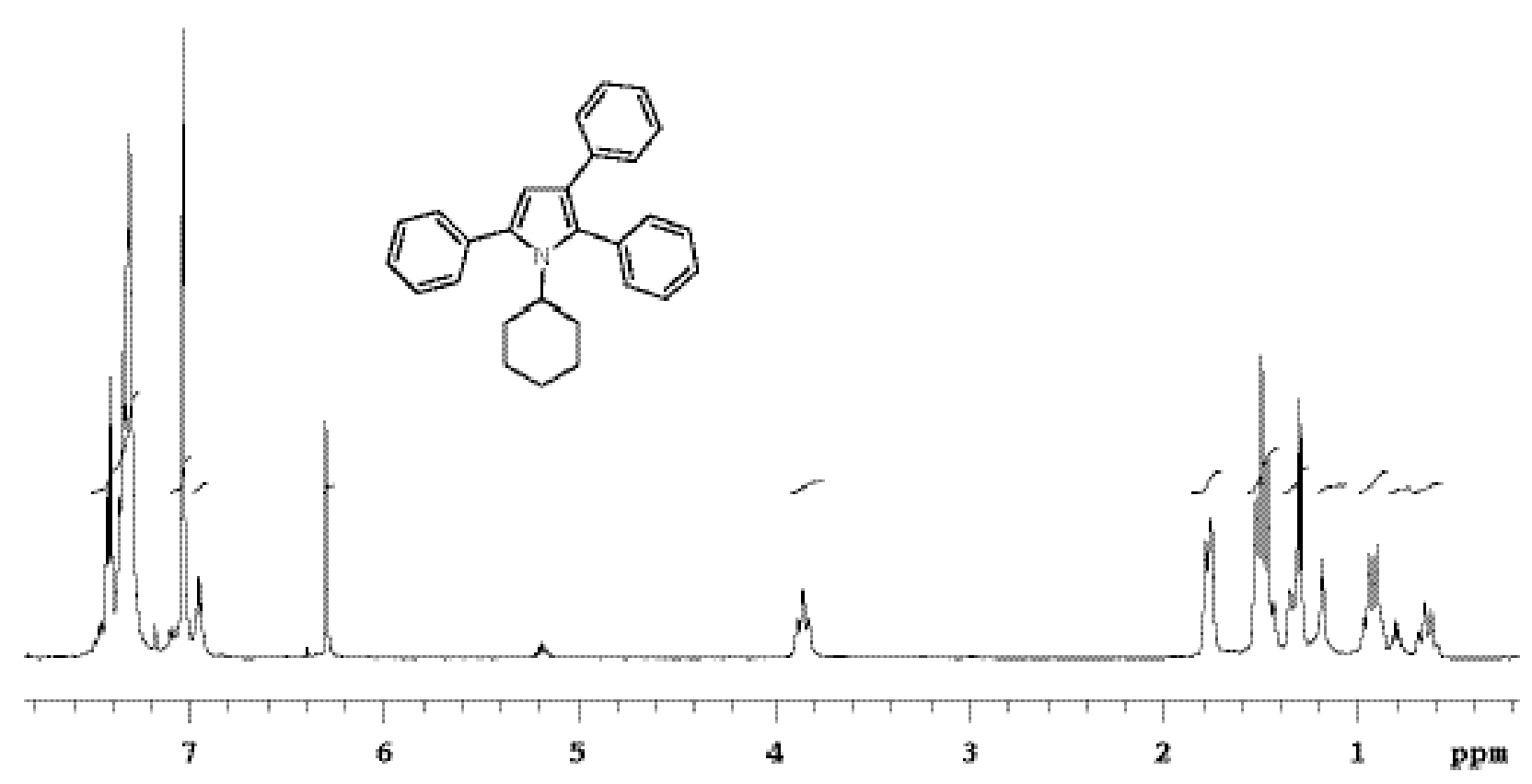

Page S22

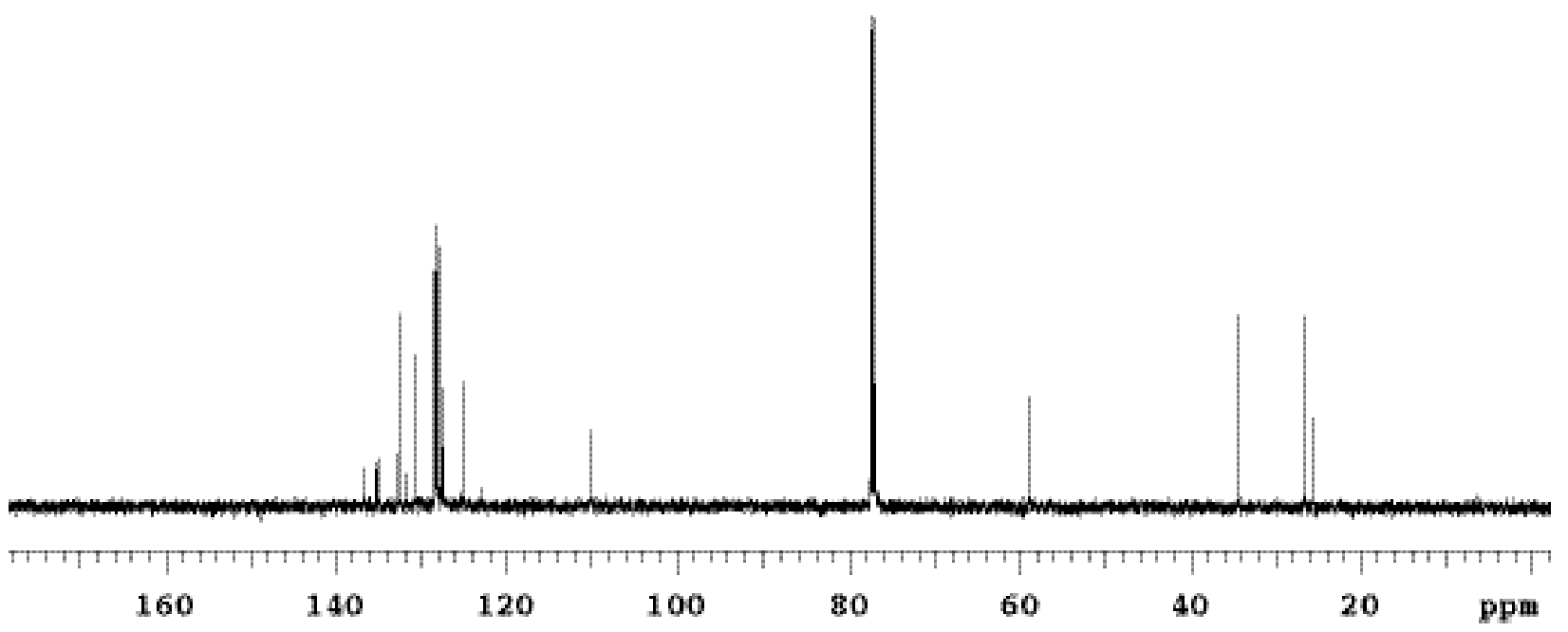



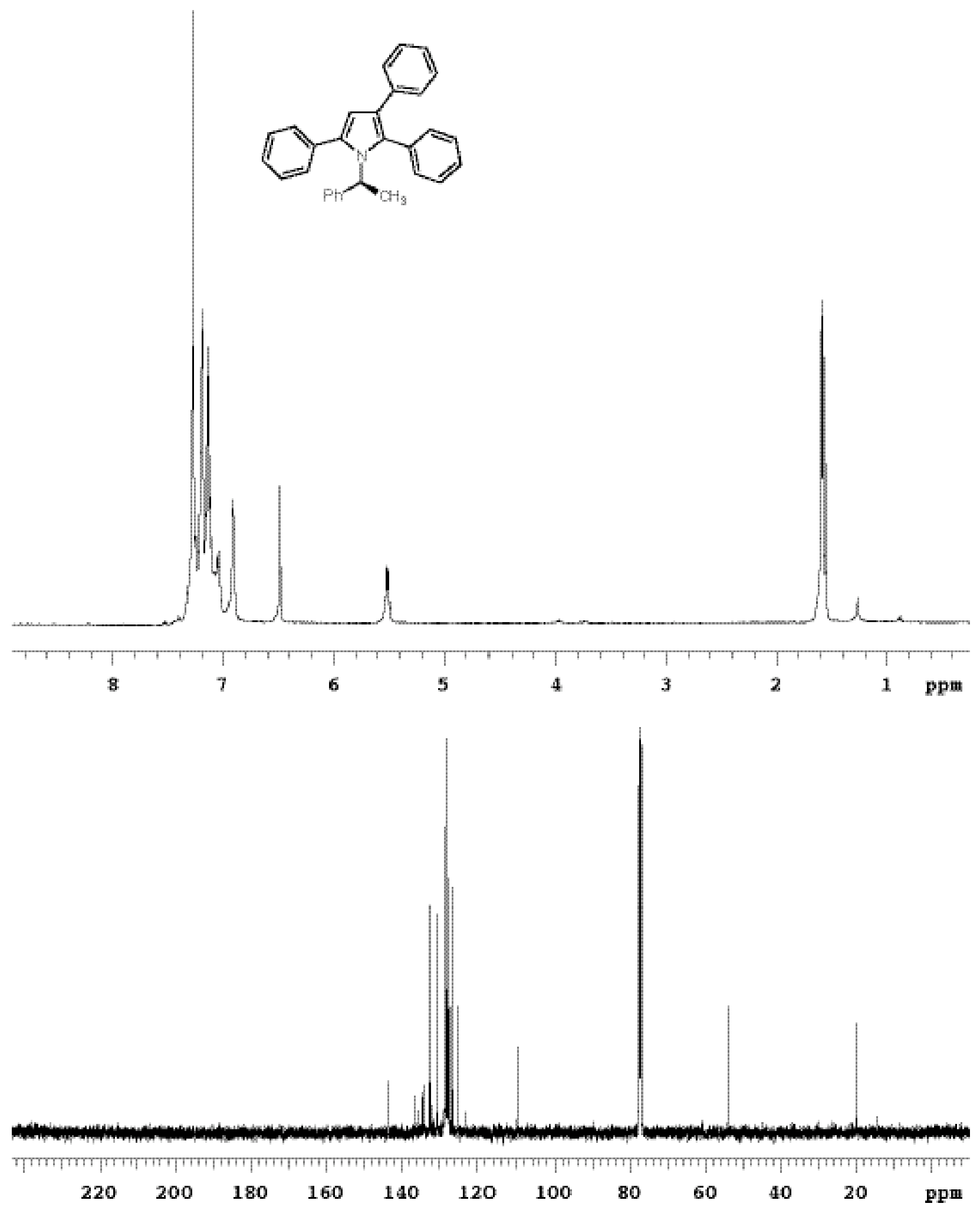

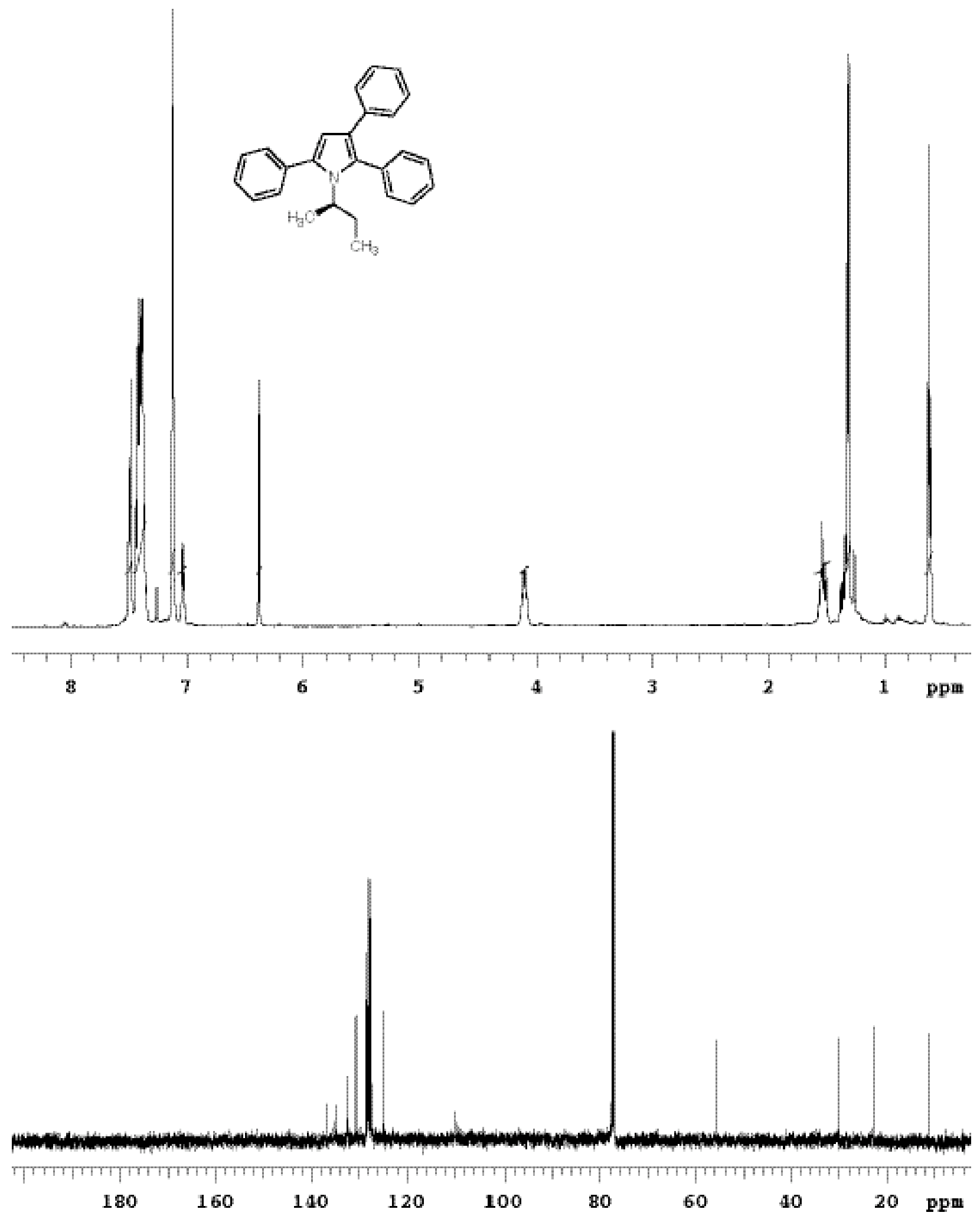


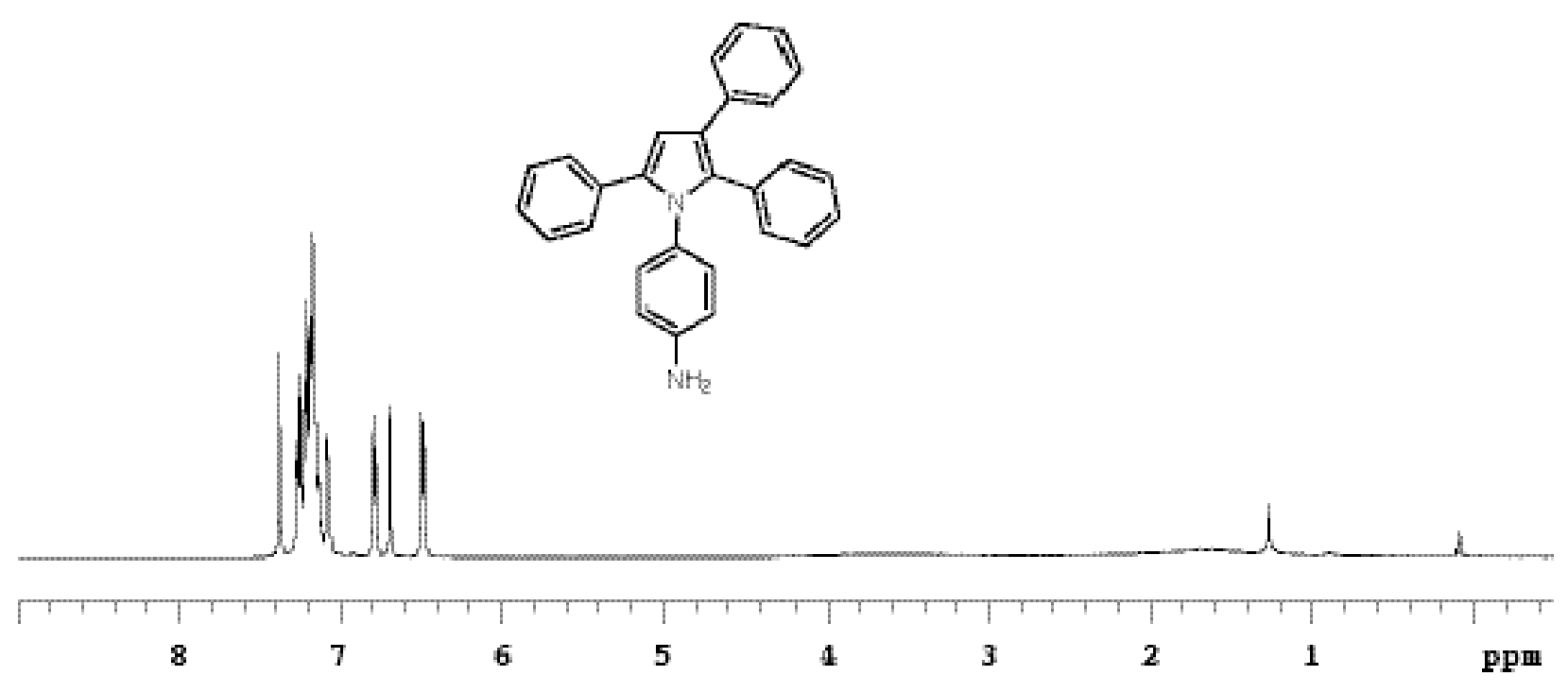

